\title{
Dynamic interactions at the mineral-organic matter interface
}

\author{
Markus Kleber ${ }^{1 *}$, Ian C. Bourg ${ }^{2}$, Elizabeth K. Coward ${ }^{3}$, Colleen M. Hansel ${ }^{4}$, Satish C.
}

B. Myneni ${ }^{5}$, Naoise Nunan ${ }^{6,7}$

${ }^{1}$ Department of Crop and Soil Science, Oregon State University, Corvallis, OR, USA.

${ }^{2}$ Department of Civil and Environmental Engineering \& High Meadows Environmental Institute, Princeton University, Princeton, NJ, USA.

${ }^{3}$ Department of Chemistry and Biochemistry, University of California San Diego, La Jolla, CA, USA.

${ }^{4}$ Marine Chemistry and Geochemistry, Woods Hole Oceanographic Institution, Woods Hole, MA, USA.

${ }^{5}$ Department of Geosciences, Princeton University, Princeton, NJ.

${ }^{6}$ Sorbonne Université, CNRS, IRD, INRA, P7, UPEC, Institute of Ecology and Environmental SciencesParis, Paris, France.

${ }^{7}$ Department of Soil \& Environment, Swedish University of Agricultural Sciences, Uppsala, Sweden

*email: Markus.Kleber@oregonstate.edu 


\begin{abstract}
Minerals are widely assumed to protect organic matter (OM) from degradation in the environment, promoting the persistence of carbon in soil and sediments. In this Review, we describe the mechanisms and processes operating at the mineral-organic interface as they relate to OM transformation dynamics. A broad set of interactions occur, with minerals adsorbing organic compounds to their surfaces and/or acting as catalysts for organic reactions. Minerals can serve as redox partners for OM through direct electron transfer or by generating reactive oxygen species, which then oxidize OM. Finally, the compartmentalization of soil and sediment by minerals creates unique microsites that host diverse microbial communities. Acknowledgement of this multiplicity of interactions suggests the general assumption that the mineral matrix provides a protective function for organic matter is overly simplistic. Future work must recognize adsorption as a condition for further reactions instead of as a final destination for organic adsorbates, and should consider the spatial and functional complexity that is characteristic of the environments where mineral-OM interactions are observed.
\end{abstract}




\section{[H1] Introduction}

The vast majority of organic carbon in the biosphere (5410 - $6545 \mathrm{PgC}$; including vegetation, permafrost, soils, coastal systems, and marine sediments ${ }^{1}$ ) occurs at solid earth interfaces in close spatial proximity to some form of mineral matter. For this reason, carbon flowing through the biosphere will at some point almost inevitably come into contact with mineral surfaces as it undergoes the many transformations inherent in the carbon cycle. Consequently, the interactions between organic and mineral phases have long been the subject of scientific inquiry. For example, most soil organic carbon is associated with colloidal [G] -sized minerals ${ }^{2,3}$, prompting early suggestions that this association is critical for soil fertility and, by extension, is "vital to life" $^{4}$. When toxic organic chemicals were found to be accumulating in the biosphere ${ }^{5}$, mineral phases were investigated for their ability to break down organic contaminants in the environment ${ }^{6-8}$. More recently, interest has turned towards using soils and sediments as repositories for excess atmospheric carbon ${ }^{9,10}$, resulting in intensive research into the mechanisms determining the formation, strength, and durability of mineral-OM associations ${ }^{10-13}$. These latter research efforts have confirmed that minerals can protect OM from degradation. However, observed correlations between individual predictor values such as clay content ${ }^{14}$ or abundance of poorly crystalline [G] minerals ${ }^{15}$ tend to be specific to certain situations and soil types. To date, no carbon cycle model has succeeded in predicting carbon turnover dynamics based on a generalised, broadly applicable set of mineral phase parameters.

Several principles are critical to understanding mineral-OM interactions. First, soils and sediments originate from a combination of destructive and constructive processes. Weathering processes and organic matter decomposition disassemble rocks and organic debris into basic molecular units, which combine to create micron-sized agglomerations ${ }^{16}$. Biotic and abiotic processes organise the resulting microfabric into a porous, internally-structured medium ${ }^{17}$. Second, minerals generally dominate over OM in soils and sediments in terms of mass proportions, with organic materials (including living organisms) rarely contributing more than single-digit percentages to total mass ${ }^{18-20}$ (although exceptions are found in organic soils and organic surface horizons). Owing to the quantitative dominance of the mineral phase, particle size distribution serves as a major constraint on the physical shape of the pore system as it evolves over time ${ }^{21}$. Third, liquid water is the most abundant phase in pore systems ${ }^{22}$, enabling geochemical and biological processes ${ }^{23,24}$. Therefore, it is useful to consider even unsaturated soils [G] and sediments as fundamentally aqueous systems. Finally, the mineral phase, the organic phase, and the pore system are habitats for biota, which constantly modify both physical shape of pores and biogeochemical activities within the system ${ }^{25}$

In this Review, we undertake a broad appraisal of the complexity of the mineral organic interface and derive a perspective for future research efforts. The diverse roles of minerals in the environment are described (Fig. 1a), including OM adsorption [G] , catalysis, chemical reactions participation, and reactive oxygen species [G] (ROS) generation. The role of the mineral matrix in creating distinct reaction spaces, and its importance of this compartmentalization [G] in the 
fate of OM, are examined. Finally, we urge the field to move towards considering mineral-OM interactions as multidimensional and multifaceted, and to reconsider the current notion of mineral protection of OM.

\section{[H1] Fundamental properties}

Mineral-organic interactions depend on several characteristic properties of the individual mineral and organic phases, which are briefly described below.

\section{[H2] Organic phase}

Organic molecules can be produced by abiotic processes ${ }^{26,27}$ and by chemotrophic microorganisms ${ }^{28}$, but phototrophic [G] algae in the oceans and vascular plants on land are responsible for the bulk of modern biomass production, in roughly equal proportions ${ }^{29}$. Primary production in the oceans creates mostly lipids, proteinaceous materials, and carbohydrates other than cellulose ${ }^{30}$, whereas lignin and cellulose together account for around half of primary production on land ${ }^{18}$.

Heterotrophic [G] organisms use the resulting biomass as a combined source of carbon, energy, and nutrients. Because cell wall passage is restricted to molecules with relatively small molecular masses $(<600-1000 \mathrm{Da})^{30}$, the size of biomacromolecules must be reduced before assimilation into the cell is possible. Depolymerization [G] and oxidation reactions inherent to extracellular molecular disassembly add ionizable oxygen-containing functional groups to decomposition products ${ }^{3}$. The resulting increasing abundances of polar functional groups (Fig. 2) enhance the aqueous solubility of the products, as well as their chemical reactivity towards metal cations and mineral surfaces, particularly when these functional groups are ionized. Moreover, the smaller molecular size facilitates diffusion ${ }^{31}$ of solubilized, reactive organic fragments towards mineral microstructures where they can become entrapped and adsorbed. Once an organic molecule comes close to a mineral surface, the abundance and type of organic functional groups constrain options for further reactions between matrix surfaces and mobile organic adsorbates.

\section{[H2] Mineral phase}

A diverse suite of minerals occur in soils and sediments, including phyllosilicates and aluminosilicates (collectively referred to as silicates); metal oxides, hydroxides, and oxyhydroxides (collectively referred to as oxides); and metal carbonates and sulfides (Figs. $3 \mathbf{~ \& ~}$ 4). In most soils and sediments, phyllosilicates are the predominant component of the finegrained fraction $[G]^{32,33}$. Metal oxides are an order of magnitude less abundant than phyllosilicates except in highly weathered systems and metal-dominated marine benthic habitats (such as hydrothermal vent deposits and ferromanganese crusts), but they contribute distinct reactivity ${ }^{22,34}$ (Fig. 4). 
Minerals possess both permanent (structural) and variable (pH-dependent) surface charge distributions. Subsequent coulombic interactions [G] dictate many physical and chemical properties, such as dispersion [G] behavior, coagulation [G] , colloidal stability, solubility, and adsorptive bonding mechanisms ${ }^{35-37}$. Mineral surface reactivity is also driven by surface topography ${ }^{38}$, which results from deviations in atomic crystal structure (such as steps or vacancies), in tandem with particle shape and size. In altering the configuration and number of reactive surface groups per unit mass, topographic surface drivers (steps, edges, and kinks, for example) can thus influence the composition, abundance, and bond strength of compounds at the mineral surface. Surface defects can facilitate the formation of stronger surface complexes or reveal edges that offer unsaturated atoms available for direct complexation ${ }^{39-42}$, and particle size modulates the relative number of reactive surface groups per unit mass of mineral. Finally, the presence and size distribution of pores within mineral grain assemblages also affects the available surface area for organic ligands, as well as exposure kinetics through steric constraints [G] and diffusion limitation ${ }^{43-46}$.

Beyond surface charge and topography, the key properties of fine-grained minerals that determine their interactions with OM (that is, mineral size, shape, charge, and covalent reactivity) are fundamentally derived from their crystal structures (Fig. 3). Notably, interfacial energies [G] of the different crystal facets [G] have a strong influence on particle size and shape 47-49. For layer-type minerals (phyllosilicates, gibbsite, and layered manganese (Mn) oxides such as birnessite), one facet carries only surface $\mathrm{O}$ atoms or $\mathrm{OH}$ groups that are fully saturated ${ }^{50}, 51$. The low interfacial energy of this crystal facet explains the tendency of the associated minerals to adopt a lamellar shape. In turn, this lamellar shape minimizes the tendency towards crystal growth [G] and hence favors the persistence of small particles ${ }^{52}$.

The iron (Fe) oxides and framework Mn oxides are exceptions to the condition presented above, in that all their crystal facets carry under- or over-coordinated surface $\mathrm{O}$ atoms ${ }^{53}$. One consequence of this imperfect surface $\mathrm{O}$ coordination state is that these minerals are primed for covalent reactions with appropriate organic functional groups. Another consequence is that these minerals tend to grow and dissolve readily, and form particles in a variety of shapes depending on the aqueous chemistry ${ }^{34}$. Finally, the relatively high interfacial energy of these minerals enables the coexistence of multiple Fe oxides in most soils, as differences in surface and bulk energies cause reversals in the order of thermodynamic stability as a function of particle size and aqueous chemistry ${ }^{47}$. For example, poorly-crystalline ferrihydrite is often the initial product of $\mathrm{Fe}^{\mathrm{III}}$ crystallization owing to its favorable surface energy. However, at sizes greater than $\sim 5 \mathrm{~nm}$ ferrihydrite becomes unstable relative to more crystalline goethite and hematite owing to its less favorable bulk energy ${ }^{48}$

\section{[H1] Adsorption}

Adsorption has long stood as an explanation for the spatiotemporal preservation of organic matter in soils and sediments ${ }^{54}$. However, mounting recognition of the dynamism occurring at the mineral-organic interface, buoyed by diversifying intersectionality in expertise 
and analytical techniques ${ }^{14,55-58}$, has emerged in the last decade of biogeochemical research. Rather than a static and irreversible binding mechanism, it is increasingly clear that adsorption itself encapsulates a series of fundamentally kinetic processes: diffusion, competition, and exchange reactions are concurrent and continuous as organic matter accumulates at the mineral surface. The dynamic mineral-OM interface evolves continuously with changes in the chemistry of aqueous phases, OM, and mineralogy, and influences both magnitude and rate of OM adsorption.

Observed complexity in OM adsorptive processes is rooted in the inherent diversity of the reactants. Organic matter encompasses a complex, heterogeneous continuum of structure, processing, and functional diversity ${ }^{59-61}$. Even among small organic compounds, this variety enables adsorption through a combination of multiple anchoring points and mechanisms ${ }^{62,63}$ (Fig. 2). In tandem, a diverse suite of mineral phases occurs in soils and sediments, varying in surface charge and distribution, topography, and particle size (Fig. 4). OM adsorption almost invariably involves a combination of several mechanisms. However, mechanisms of organomineral adsorption can be grouped by the surface chemistry of the mineral (Fig. 5), as it affects surface-ligand bond types, coordination state, and spatial organization. These surface chemistries fall into three general groups: variably-charged, non-charged, and negatively charged.

Variably-charged surfaces of metal oxides and phyllosilicate crystallite edges carry hydroxyl groups that are increasingly protonated with decreasing $\mathrm{pH}$, thereby acquiring positive charge. This protonation, in turn, enables the retention of organic ligands through rapid ligandexchange ${ }^{64,65}$. In many phyllosilicates, substitution of octahedral aluminum (Al) and tetrahedral silicon ( $\mathrm{Si}$ ) with cations of lesser charge will generate permanently charged surfaces. The prevailing negative charge of these surfaces allows for electrostatic attraction of metal cations ${ }^{66}$. When isomorphic substitution is absent, as in some 2:1 phyllosilicates and kaolin-group minerals, the resulting surfaces are electrostatically neutral and thus allow nonpolar organic molecules to accumulate via entropy-driven hydrophobic exclusion phenomena in combination with Lifshitz - van der Waals forces and H-bond formation ${ }^{3,67}$ (Fig. 5).

As organic ligands partition from solution [G] to mineral surfaces, monolayer coverage of the mineral surface converges into a multilayer molecular architecture ${ }^{68,69,70}$ (Fig. 5). Organic ligands tend to have a variety of functional groups (Fig. 2), thus there can be multiple bonding mechanisms between the mineral and OM. This diversity of bonding reactions, paired with the competition of organic compounds for sorptive sites both between themselves and with inorganic ions $^{71}$, results in complex multidimensional structures at the mineral surface (Fig. 5). Ion concentrations are well known to modulate adsorption rates and extents, with variations amongst bonding mechanisms and ion composition ${ }^{72,73}$. However, the importance of competition between organic compounds in structure-selective adsorption (molecular fractionation) is less wellconstrained.

Similarly, a plethora of recent work has probed the formation and structure of this multilayer over a range of time and length scales based on nanometer-scale microscopy and 
spectroscopy ${ }^{74}$, temporal partitioning of organic ligands from solution onto the mineral surface 75,76 , and detection of uneven structures at the mineral surface ${ }^{77-79}$.

Adsorption of $\mathrm{OM}$ at the mineral-water interface occurs at a rapid rate and reaches equilibrium with aqueous phase in 24 hours for many organic moieties and non-porous minerals 80. The initial adsorption step is typically fast, and a majority of adsorption is completed within the first few hours after the solid-phase is exposed to aqueous OM. Slow adsorption can follow this first step and is most likely caused by the diffusion of molecules into the intra-particle regions [G] ${ }^{45,65,81}$. Most kinetic datasets regarding OM sorption on soils and sediments come from studies conducted on xenobiotic compounds [G] ${ }^{65}$. However, studies carried out on organic molecules isolated from soil and aquatic environments suggest that the variables that control the magnitude of sorption, also control its kinetics ${ }^{82,83}$. Some of these variables include the size, charge, hydrophobicity, charge density, and concentration of OM, solution composition ( $\mathrm{pH}$, ionic strength, ion type), and mineral type (such as metal oxides versus silicates). For example, rapid adsorption is more common at lower $\mathrm{pH}$ values, high $\mathrm{OM}$ concentration, and in the presence of cations ${ }^{82-85}$, where adsorption rates are faster under conditions that promote weaker adsorption affinity, such as in alkaline solutions ${ }^{83}$. Notably, newly adsorbed organics might compete with and actually induce the release of previously adsorbed organic compounds ${ }^{86}$, though this process is not well studied in situ.

Once bound to a mineral surface, an organic ligand [G] only rarely remains undisturbed and instead is vulnerable to desorption and exchange processes, mineralization, and catalytic transformations in situ (Fig. 6). During these processes, organic molecules on mineral surfaces might experience changes to their hydration, structure, isomerization, rotation, and electron delocalization, depending on the type of chemical bonding at mineral-water interface. The overall chemical or electronic state of the adsorbed molecule tends to be similar to the molecule in solution when the adsorbed molecules exhibit H-bonding, Van der Waals interactions, or retain their solvated water (Fig. 6). Conversely, the adsorbed molecule tends to experience substantial changes to its chemical state if it forms covalent or ionic interactions and directly coordinates to the metal atoms at the mineral-water interface, such as during ligand-exchange. These distinct responses are relevant to hydrolysis, electron transfer, and radical mediated reactions, as well as photochemical lability [G] ${ }^{87,88}$. Although electron transfer amongst weaklycoordinated species can be limited in some of these complexes, for directly-bound covalent complexes, not only the chemical state of the organic molecule is changed but also the electronic state of the metal atom on the surface (Fig. 6). Unlike alkali and alkaline earth elements, transition metal ions in solution or at mineral-water interfaces, such as $\mathrm{Mn}, \mathrm{Fe}, \mathrm{Ni}, \mathrm{Cu}$, and $\mathrm{Zn}$, play an important role in modifying the electronic states of the interacting organic functional groups ${ }^{89-91}$.

Adsorption potentially impacts not just the adsorbed OM, but also the minerals: adsorption invariably lowers interfacial energy ${ }^{92}$, so accumulation of OM on mineral surfaces should both facilitate the nucleation [G] of new particles and inhibit the growth of existing particles. This should favor the formation and persistence of smaller particles, a phenomenon observed 
experimentally in the apparent stabilization of short-range-ordered [G] (SRO) metal oxides (ferrihydrite) and aluminosilicates (proto-imogolite) ${ }^{93-96}$. A logical consequence of this is that correlations between $\mathrm{OM}$ and fine-grained minerals, though generally interpreted as reflecting the impacts of minerals on OM, should additionally reflect (to an unknown extent) impacts of OM on mineral nucleation, growth, and transformation.

The transformations summarized here, and the subsequent temporal persistence of adsorbed molecules, are critical to parameterization of organic $\mathrm{C}$ cycling in environmental systems. Yet, comparatively few studies have assessed the susceptibility of organic ligands to desorption and exchange despite widespread attribution of adsorptive temporal persistence 12,58,97,98. Even relatively short desorption experiments using minerals and whole soils reveal partial removal of adsorbed ligands from all surfaces except variable-charge hydrous oxides. However it is likely that there is continuous exchange even with these minerals, masked by nearzero net solubility ${ }^{58,99}$. Mineral transformation and dissolution could also mediate release of adsorbed compounds into the aqueous phase. Anoxic events and biotic reductive dissolution of oxides ${ }^{100-104}$, acidity-driven deprotonation in low-Fe systems ${ }^{105}$, and secretion of root exudates ${ }^{106,107}$ could all serve a weathering-like role in releasing adsorbed ligands.

A presumed link between particular bonding mechanisms and biotic mineralization of ligands has not been systematically addressed. Laboratory biodegradation studies suggest OM adsorption, particularly to high-surface area oxides in low-pH systems ${ }^{108-111}$, can hinder decomposition. It is not clear, however, how such findings translate to natural soils and sediments, where dynamic weathering and solution chemistry will alter surface functionality, and where exoenzymes from fungi and bacteria can be abundant in solution. Indeed, whole-soil isotope tracer experiments suggest that metabolism of adsorbed ligands is continuous ${ }^{112}$. Besides microbial degradation and consumption after direct desorption, displacement by biotic exudates can contribute to the decomposition of previously-adsorbed molecules ${ }^{113}$, supported by observations that a substantial proportion of mineral-adsorbed organic matter is microbial in origin ${ }^{114-116}$. Such evidence for the multifaceted role of biotic consumption, exchange, and deposition of organic ligands highlights the uncertainty in underlying controls and their quantitative effect on mineralization rates.

\section{[H1] Catalysis}

The potential of a mineral surface to act as a catalyst [G] and enhance reaction rates results from the combined action of multiple factors. For instance, minerals can concentrate organic compounds to several orders of magnitude higher than the bulk solution ${ }^{11,118}$, thus increasing the pre-exponential frequency factor in the Arrhenius equation. Association with a mineral surface can reduce the degree of orientational freedom [G] of an adsorbate by aligning monomers along two dimensions at planar surfaces ${ }^{119}$, thereby facilitating recurring reaction patterns. Minerals also create centers of reactivity by providing coordinatively unsaturated sites and steric enhancement [G] of reactions at surfaces with substantial topography ${ }^{38}$. Furthermore, 
mineral surfaces can transfer protons to a sorbate as well as offer empty electron orbitals for the reception of bonding electron pairs (Broensted- and Lewis-acid/base functionalities ${ }^{120}$ ). Lastly, minerals entirely made of transition metals (such as $\mathrm{Fe}$ and Mn oxides) or acting as solid supports for adsorbed transition metals at their surfaces and in interlayers (phyllosilicates) can contribute transition metal specific catalytic functionality ${ }^{121,122}$.

Laboratory observations made on the catalytic reactivity of different minerals can be used to recognize three mineral types of chemical reactivity (Fig. 6), although the intensity of the organomineral interactions within each class varies with changes in mineralogy, OM concentration, and geochemistry of the environment.

Class I minerals are dioctahedral 2:1 clays that adsorb large organic molecules through cation-bridging and through hydrophobic expulsion and aromatic ring $\pi$-interactions with surfaces or Lifshitz - van der Waals forces. Direct complexation of OM can occur at edge sites. Because hydrophobic expulsion is the primary driver for adsorption, kinetics of adsorption are fast, macromolecular structures are rarely disturbed, and limited electron transfer is expected. However, heterogeneous oxidation of OM can occur on clay surfaces in the presence of adsorbed $\mathrm{O}_{2}$ and transition metals ${ }^{123,124}$. Overall, the catalytic activity of Class I minerals is expected to be low with slow kinetics ${ }^{123,125}$.

Class II minerals are metal oxides, silicates, and 1:1 clays, and exhibit high adsorption capacity (Fig. 6). These minerals tend to catalyze moderate changes to the structure and electronic state of adsorbed molecules, primarily through direct bonding, hydrolytic breakdown from reactions with surface $\mathrm{OH}$, and heterogeneous oxidation with adsorbed $\mathrm{O}_{2}{ }^{123,126,127}$.

Finally, Class III minerals are highly reactive in terms of magnitude of sorption, and in terms of hydrolytic and electrolytic breakdown and heterogeneous oxidation (Fig. 6). Reduced clays (those with substituted transition metals), Mn oxides, sulfides and magnetite belong to this category ${ }^{123,127-129}$. Mineral carbonates and sulfides, through major changes of surface acidity at the interface, play an important role in the hydrolytic breakdown of macromolecular organic molecules. Breakdown of large molecules into small molecules is possible, as is the subsequent transformation into larger molecules through nucleophilic addition, radical mediated polymerization and large molecule formation reactions (Fig. 6 $^{129-131}$ ). Because of these changes, substantial alterations to mineral surface structure, including even eventual dissolution, are anticipated in the case of Class III minerals (Fig. 6). Strongest proof for all of these observations comes from solution studies, rather than from spectrometric work directed at the interface ${ }^{123,132,133}$. The solution studies reveal the progress of catalytic reactions and their rates; however, not the reaction mechanisms at the interface.

The impact of mineral catalytic behavior on OM stability is expected to be greater where there is direct organomineral interaction, or where there are monolayer coverages of OM (Fig. 6). As a consequence, the intensity of organomineral interactions should be strongest during monolayer OM adsorption. In multilayer adsorption, conversely, the overall role of minerals as catalysts should be comparatively diminished as OM-OM interactions increasingly predominate over mineral-OM interactions (Fig. 6). Although a majority of molecular studies conducted on 
soils or sediments belong to the latter category ${ }^{74,134,135}$, the impact of layer thickness on OM behavior remains relatively poorly understood because of the analytical difficulties in exploring these systems.

Metal atoms of mineral surfaces in the proximity of adsorbed molecules also tend to experience changes to the adsorbed water and surface hydroxyls, and to their electronic state. These can be three-fold: changes in the metal-ligand coordination (and hydration and hydrolysis) environment; complete e-transfer and oxidation or reduction of surface metal atoms; and perturbations to the energy levels of valence electrons ${ }^{133,136,137}$. Although changes are less notable during the formation of weak H-bonded complexes, the formation of direct ionic and covalent interactions impact the binding of metal atoms of mineral surface strongly, with some additional impact to the buried atom layers next to the binding site ${ }^{38}$ (Fig. 6). As a result, adsorption of OM to mineral surfaces often modifies the characteristics of both OM and mineral surfaces, and only in rare occasions are the chemical characteristics of each preserved at the interface during bonding ${ }^{38,85,130}$. These considerations highlight the difficulty to distinguish between two fundamental functions (catalysis and redox reactions) of mineral surfaces when considering OM transformations at solid earth interfaces. At this time, it seems there is considerable conceptual uncertainty regarding these functions, with the available evidence favoring a role as reactant.

\section{[H1] Redox reactions}

Electron transfer reactions between OM and minerals, directly or mediated by microbes, are a primary pathway contributing to the oxidation, transformation, and mineralization of carbon within soils and sediments (Fig. 7a). Minerals and OM can serve as either electron donors or acceptors for a vast array of heterotrophic or mixotrophic [G] microbial metabolisms spanning a broad ecologic and taxonomic diversity ${ }^{138}$. Various mechanisms are employed in the microbial coupling of organic carbon oxidation to the reduction of Fe and $\mathrm{Mn}$ oxides, including direct electron transfer via outer membrane enzymes ${ }^{139}$ or conductive nanowires [G] ${ }^{140,141}$ and indirect transfer via endogenously produced electron-shuttling molecules that are secreted by an organism after which they adsorb to an oxide surface and transfer the bacterial-derived electron to the mineral ${ }^{142}$. The latter reaction pathway is a coupled biotic-abiotic pathway, whereby the second step is a direct electron transfer reaction between the organic molecule and mineral surface.

A variety of organic molecules can be transformed via direct electron transfer at the surface of minerals, including Fe and Mn oxides, sulfides, and phyllosilicates ${ }^{123}$. Within natural systems, metal oxides have garnered particular attention for their ability to serve as effective oxidants of a wide range of organic compounds ${ }^{143}$, including humic acids, phenols, anilines, low molecular weight organic acids (such as oxalate, pyruvate, citrate) ${ }^{7,144,145}$, and more recently proteins ${ }^{128,146}$. The overall reaction sequence involves adsorption of the organic reactant to the 
(hydr)oxide surface, transfer of electron(s) to the mineral-hosted metal, and subsequent detachment of the reduced metal and oxidized organic molecule ${ }^{123}$.

The adsorption, fractionation, and oxidative transformation upon reaction of dissolved organic matter with minerals are dependent on mineral surface chemistry, including the composition and abundance of terminal bonds ${ }^{123,147}$. Despite typically lower adsorptive capacities, Mn oxides are stronger oxidants than Fe oxides, in large part owing to differences in redox potential ${ }^{123,148,149}$. Indeed, Mn oxides are considered the strongest naturally occurring oxidants, and thus considerable attention has been placed in investigating the role of Mn oxides in organic carbon transformations ${ }^{143}$. In general, organic compound oxidation rates increase with average oxidation state, redox potential, and specific surface area of the Mn oxide and decrease with apparent activation energy of the overall reaction and the $\mathrm{pH}_{\mathrm{pzc}}$ of the oxide ${ }^{143}$. Furthermore, OM oxidation rates increase with decreasing $\mathrm{pH}$, which has been primarily attributed to the higher redox potential at lower $\mathrm{pH}$.

As mineral-OM redox reactions rely on surface complex formation ${ }^{150}$, the efficacy of mineral-induced organic matter oxidation and mineralization is ultimately determined by factors controlling initial adsorption. Thus, the extent and rates of organic carbon transformation and mineralization at mineral surfaces decline if surfaces become passivated [G], for instance by high organic matter loadings ${ }^{123}$ and/or reaction products blocking reactive sites on the surface ${ }^{143}$. Further, mineral ripening [G] and recrystallization to less reactive phases during reaction can constrain mineral surface reactivity over time. Extrapolation of the rates and products of mineralmediated OM transformations within natural systems from these reactions involving pure phases is therefore limited and convoluted.

Nevertheless, correlations between oxidized Mn and oxidized OM point to a causal link between Mn oxidation and carbon transformations ${ }^{113,149,151}$. In fact, the intimate and diverse association of OM with Mn oxides ${ }^{149,152}$ leads to a continuum of reactions, including mineralization and polymerization within layers coating the oxide surface ${ }^{129}$. Yet beyond correlations, there is limited data directly linking natural Mn oxides (or any mineral) to OM oxidation and transformation, pointing to a clear need for future investigations targeting mineralmediated OM redox mechanisms.

\section{[H1] Reactive Oxygen Species}

Mineral-derived $\operatorname{ROS}^{153}$, particularly hydrogen peroxide $\left(\mathrm{H}_{2} \mathrm{O}_{2}\right)$, superoxide $\left(\mathrm{O}_{2}{ }^{-*} / \mathrm{HO}_{2}\right)$, and hydroxyl radical $\left(\mathrm{HO}^{\circ}\right)$, represent likely important but currently underappreciated players in the transformation of soil and sediment organic matter ${ }^{154}$. Among various biological and (photo)chemical processes ${ }^{155,156}$, common soil and sediment minerals have also demonstrated the ability to produce ROS, including $\mathrm{H}_{2} \mathrm{O}_{2}$ and $\mathrm{HO}^{\bullet}{ }^{157-161}$. These ROS-producing minerals include primary silicates (such as plagioclase), oxides, sulfides, and clays, with the titanium dioxide phases rutile and anatase $\left(\alpha-\right.$ and $\left.\beta-\mathrm{TiO}_{2}\right)$, iron oxide hematite $\left(\alpha-\mathrm{Fe}_{2} \mathrm{O}_{3}\right)$, and $\mathrm{Fe}(\mathrm{II})$ bearing clays such as biotite and chlorite having the highest ROS yields observed to date ${ }^{157,161}$. 
Minerals contribute to ROS production via water and $\mathrm{O}_{2}$ reaction at defect sites or with mineralhosted or adsorbed $\mathrm{Fe}(\mathrm{II})$, and via photochemical electron transfer ${ }^{158,161,162}$ (Fig. 7b-c). Alternatively, the reductive or oxidative dissolution of minerals leads to the release of metals (particularly iron) or ligands (particularly sulfide) that can create ROS upon reaction with oxygen ${ }^{158}$ (Fig. 7b). Thus, albeit limited in number, these investigations of mineral-derived ROS indicate that the mechanisms and pathways of ROS formation vary as a function of the mineral, light, and aqueous environment.

Mineral-derived ROS within natural soils and aquifers have been measured in a limited number of investigations. In subsurface soils and groundwaters, fluctuating redox conditions and oxygenation of $\mathrm{Fe}$ (II)-bearing minerals are the primary contributors to ROS production ${ }^{161,163}$. Formation of ROS including $\mathrm{O}_{2}{ }^{--}$and $\mathrm{HO}^{*}$ has been linked to the oxidation of aqueous $\mathrm{Fe}(\mathrm{II})$ emanating from subsurface marine ${ }^{164}$ and lake sediments ${ }^{165}$. Indeed, the oxygenation of reduced soils, sediments, and waters results in a cascade of ROS pathways, including initial formation of both $\mathrm{O}_{2}{ }^{--}$and $\mathrm{H}_{2} \mathrm{O}_{2}$, ensuing dismutation of $\mathrm{O}_{2}{ }^{-{ }^{-}}$to $\mathrm{H}_{2} \mathrm{O}_{2}$, and ultimately formation of $\mathrm{HO}{ }^{\circ}$ via reaction of aqueous $\mathrm{Fe}(\mathrm{II})$ and $\mathrm{H}_{2} \mathrm{O}_{2}$ (Fenton reaction) ${ }^{166}$. In sunlit surface environments, photochemical reactions at oxide surfaces have also been found to play an important role in ROS (particularly $\mathrm{O}_{2}{ }^{--}$and $\mathrm{H}_{2} \mathrm{O}_{2}$ ) formation, including in both desiccated and wet desert soils ${ }^{159}$. Production of ROS in soils pre-washed to remove photosensitizers such as nitrate point to direct mineral-induced ROS generation upon irradiation ${ }^{159}$. Superoxide and peroxides can be stabilized within desiccated soils via complexation to metal oxide surfaces ${ }^{159}$. These ROS are rapidly released when soils are (re)saturated, leading to pulses of oxidants within pore waters. Thus, several oxidants are formed upon oxygenation of soils and sediments, the species and flux controlled by mineral composition and mechanism of ROS generation.

ROS vary in their selectivity and reactivity toward carbon functional groups, and react with a wide range of organic compounds, including carbohydrates, fatty acids, and biomolecules (such as DNA and proteins ${ }^{167}$ ). The reaction progression upon interaction of DOM and ROS ranges from partial oxidation of organic carbon compounds and formation of low molecular weight organic acids to complete oxidation to $\mathrm{CO}_{2}$, depending on the reactants and conditions (such as $\mathrm{pH}$ ). Aromatic moieties, such as quinones or humics, have been identified as primary sinks for $\mathrm{O}_{2}{ }^{-*}$ in marine DOM, the reaction of which could lead to a catalytic cycle regenerating the original reactant and forming $\mathrm{H}_{2} \mathrm{O}_{2}{ }^{168}$. Hydroxyl radical is a particularly unselective and strong oxidant ${ }^{169}$, having high reaction rates with $\operatorname{DOM}\left(10^{8} \mathrm{M} \mathrm{C}^{-1} \mathrm{~s}^{-1}\right)^{170}$ and the ability to oxidize carbon compounds within the DOM pool that are otherwise difficult to photo- or biodegrade ${ }^{171,172}$.

Although indirect evidence points to probable contributions of mineral-derived ROS in carbon processing, few studies to date have directly interrogated the role of ROS in carbon transformation and degradation. Still, the potential for ROS to be quantitatively relevant in carbon cycling was exemplified by a previous investigation where rates of $\mathrm{CO}_{2}$ produced from ' $\mathrm{OH}\left(109 \mu \mathrm{mol} \mathrm{CO} \mathrm{C}^{-2} \mathrm{~d}^{-1}\right)$ in Arctic soils were found to be on the same order of magnitude as bacterial mineralization of DOM in surface waters ${ }^{165}$. Similarly, DOM (including coloured 
DOM) is a predominant sink of $\mathrm{O}_{2}{ }^{--}$within several marine systems ${ }^{173,174}$, and photodecomposition of DOM in lake waters has been linked to ROS formation ${ }^{175}$. One of the first studies to directly link ROS to remineralization of carbon within soils showed that ${ }^{\circ} \mathrm{OH}$ derived from $\mathrm{Fe}$ (II) oxidation was responsible for DOM oxidation to $\mathrm{CO}_{2}$ in Arctic soils ${ }^{154}$. Specifically, production of $\mathrm{CO}_{2}$ in Arctic soil incubations scaled with ${ }^{\circ} \mathrm{OH}$ production stimulated via $\mathrm{H}_{2} \mathrm{O}_{2}$ addition. Similarly, stimulation of carbon mineralization within aerobic incubations of humid and tropical soils amended with Fe(II) pointed to contributions from Fenton based reactions and $\operatorname{ROS}^{57,176}$. In support of this, carbon mineralization decreased $\left(8 \%\right.$ less $\mathrm{CO}_{2}$ compared to controls) within these incubations upon the addition of ${ }^{\circ} \mathrm{OH}$ scavengers, further implicating ${ }^{\circ} \mathrm{OH}$ as a terminal oxidant of $\mathrm{OM}^{57}$. Similarly, addition of superoxide alone or in combination with $\mathrm{Fe}$ to soil incubations triggered ${ }^{\circ} \mathrm{OH}$ formation and concomitant degradation of soil organic matter ${ }^{177}$. Oxidation of tetracycline to $\mathrm{CO}_{2}$ was also recently linked to ${ }^{\circ} \mathrm{OH}$ formation upon oxidation of sediments in lab incubations ${ }^{161}$. Lastly, soil organic matter oxidation and decomposition in the absence of enzymatic activity (inactivation via autoclaving) within soils implicated mineral-derived ROS ${ }^{56,178}$; yet, the mechanism at play was not elucidated.

\section{[H1] Definition of microbial habitats}

Mineral-organic matter associations play a critical role in structuring and compartmentalizing the biological reaction space of soils and sediments into microsites [G] , and, in combination with the water potential, determine the extent to which the individual microsites are connected ${ }^{179}$ (Fig. 8). Pore connectivity, morphology, and size distribution at the microsite scale either enhance or restrict microbial access to $\mathrm{OM}^{180}$. They also determine the conditions that microbial decomposers are exposed to, impacting the range and magnitude of the microbial activities that occur. For instance, the compartmentalisation of space results in the juxtaposition of microsites with different environmental conditions that can be mutually exclusive (for example, oxic and anoxic) at very fine scales such as within a single aggregate 171,172 . This juxtaposition leads to the emergence of gradients, allowing a range of processes to proceed. It also facilitates the development and persistence of extensive microbial diversity, because interactions that tend to reduce diversity, such as competition for resources or antagonism, are attenuated in compartmentalised space ${ }^{173,174}$ (Fig 8). Understanding the link between microbes and their environment is fundamental to understanding soil and sediment microbial ecology, microbial activity and the involvement of microbial decomposers in OM dynamics ${ }^{16,199,200}$. As many of the functional properties of soils and sediments (nutrient cycling and pollution degradation, for example) emerge from the diversity of their microbial inhabitants ${ }^{175}$, it is not unreasonable to suggest that this functioning is ultimately dependent on the minerals' role in the structuring of space.

Indeed, we posit that the overriding function of mineral matrices (Tier 1 in Fig. 1b) should be seen in their role in compartmentalizing the system. Microbially driven decomposition 
requires decomposers and organic substrates to encounter one another ${ }^{201}$. However, OM is heterogeneously distributed at scales that are relevant for microbial decomposition ${ }^{202}$, as are microbial communities themselves ${ }^{203}$. This distribution results in a patchwork of cold and hotspots of microbial activity ${ }^{204}$, which is a fundamental characteristic of soils. Furthermore, there can be non-linear, concave relationships between the concentration of available organic substrate and microbial activities. These can be particularly apparent in activity hotspots and are possibly related to the saturation of cellular transport systems or local $\mathrm{O}_{2}$ limitations ${ }^{132}$. A major consequence of non-linear, concave relationships between the concentration of available substrate and decomposition result is the lowering of overall organic matter decomposition relative to when substrate and decomposers are homogeneously distributed ${ }^{132}$.

The variable connectivity of the microsites (Fig. 8) means that microbial communities function and evolve more or less independently of communities in other microsites and under different environmental conditions ${ }^{176,177}$. Taxa that are better adapted to the prevalent microsite conditions, such as through the capacity to use electron acceptors other than $\mathrm{O}_{2}$ in anoxic conditions ${ }^{178}$, can competitively exclude other, less adapted taxa, with the potential loss of metabolic capacity from the community. Metabolic capacity can also be lost when mutations cause the inactivation of genes that are not maintained by selective pressure (in essence, the gene does not provide any benefit to the microbe in the microsite) or genetic drift ${ }^{179}$. Such losses of capacity from microsites could have consequences for subsequent organic matter dynamics, as they would allow organic molecules to persist over time, regardless of the intrinsic properties of the molecules or the microsite conditions.

Just as plant roots affect and select microbial communities within their sphere of influence, the rhizosphere, minerals also exert influence over the microbial communities within their vicinity, and therefore the metabolic pathways and organic matter dynamics that are present in microsites ${ }^{185}$. The sphere of influence of minerals has been termed the "mineralosphere" ${ }^{186}$. For example, different types of minerals select different microbial communities ${ }^{187-189}$, and the selective pressures exerted by minerals can even be greater than those associated with different environmental conditions or in the presence of different organic matter sources ${ }^{188,190}$. Minerals, therefore, should not be viewed simply as supporting surfaces onto which microbial communities arrive from the surrounding environment in a random and passive fashion. The selective pressure exerted by minerals is likely derived from differences in resource availability at the surface or in the vicinity of the minerals induced by their function as a mobilisation filter, from the mineral acting as an electron acceptor or donor ${ }^{191}$, from differences in surface charge, area, or topography ${ }^{192}$. Microbial attachment to mineral surfaces can also trigger wholesale changes in microbial functioning, with metabolic activity being either stimulated or inhibited, or growth and biofilm formation being promoted or suppressed, depending on the mineral type ${ }^{193,194}$ and depending on the microorganism ${ }^{195,196}$. The types of microbial metabolic pathways present at mineral surfaces is likely to have a major impact on mineral-organic matter associations and, indeed, a number of studies have suggested that a large part of mineral associated organic matter has been processed by microbial communities ${ }^{109,197},{ }^{181}$ particularly in agroecosystems or in 
contexts where microbial communities flourish ${ }^{182,183}$. Furthermore, the extent to which microbially processed organic matter associates with minerals could even depend upon the composition of the microbial communities ${ }^{198}$. The mechanisms underlying the production of mineral associated organic matter via microbial processing remain as yet un-elucidated however. Nevertheless, the overriding message that emerges from these studies is that microbial communities not only mineralise organic matter but are also agents in the generation of mineralorganic matter associations.

Ultimately therefore, the properties, including the biotic composition, of the compartmentalized space are intimately linked to microbial-mineral associations. These properties affect the local environmental conditions, which, in turn, modulate subsequent biogeochemical processes ${ }^{184}$. This kind of functioning, in which feedback controls are prominent and in which the overall performance of the system is not reflected in the properties of the individual components, but emerges from the component interdependencies, is typical of complex systems ${ }^{184,185}$. The feedback controls impose a number of static and dynamic constraints on the system (Tier 2 in Fig. 1b). These constraints then determine the intensities and rates at which molecular scale biogeochemistry might be able to proceed (Tier 3 in Fig. 1b). Depending on the extent to which higher level (Tier 1 and 2) constraints operate in different parts of the system, different lower tier processes could occur simultaneously within the same system. How the structuring of space into a network of more or less connected microsites affects the assembly of microbial communities and determines local environmental conditions that modulate the expression of microbial functions and, ultimately, ecosystem performance has not yet been fully explored.

\section{[H1] Summary and future perspectives}

The mechanisms underlying mineral-organic interactions have a long tradition of being explored through adsorption experiments conducted with defined phases in tightly controlled laboratory environments. However, we strongly urge that this research take a more holistic, multidimensional view (Fig. 1b). We advise the scientific community to resist the temptation to attribute given manifestations of carbon dynamics to a single predictor value, such as the abundance of a certain mineral species, phyllosilicate clay content, or operationally determined specific surface area values, as has been frequent practice in the past. Rather, soils and sediments should be investigated as multidimensional entities, whose overall functional performance depends on the extent to which the structure of the matrix supports molecular scale reactions. Translating this insight into novel modeling approaches will be key to improved predictions of global biogeochemical cycles. Quantitative information about pore size, pore morphology and pore connectivity can be obtained from modern multidimensional imaging techniques such as computed tomography, rendering an explicit consideration of architectural features fundamentally possible. In this final section, we examine some of the outstanding questions and pressing research needs in organomineral interaction research.

\section{[H2] Structure and prokaryotic performance}


Interactions within the mineral-organic matter complex not only have immediate and direct effects on organic matter dynamics as described above but might also have indirect and longer term consequences. Metabolic dependency [G] , when microbial cells lose the ability to produce essential metabolites and instead use those released into the environment by other cells, is common in natural microbial communities ${ }^{179,180}$. Such metabolic dependency develops only if communities remain spatially co-located long enough for coevolution to occur ${ }^{181,182}$. Metabolic dependency has been shown to evolve in experimental populations in 1000 to 2000 generations ${ }^{186}$. In soils and sediments, the probability of such co-evolutionary interactions occurring is greater if the physical structure of the microsite persists over time (Fig. 8). Microsite persistence is related to the organic matter content ${ }^{183}$, but could also be related to the mineralogy. For example, there is evidence to suggest that 1:1 clays and oxides produce more persistent microsite structures ${ }^{183}$, probably owing to electrostatic interactions between the variable charged minerals ${ }^{184}$. In view of the suggestion that the persistence of organic matter in soil is related to the heterogeneous distributions of organic substrate and metabolic capacities ${ }^{187,188}$, it would be interesting to test the hypothesis that the mineral compartmentalizing the environment affects the distribution of metabolic capacity at the microsite scale. This could be achieved using shotgun metagenomics ${ }^{189}$, at appropriate scales, in soils with different mineralogies.

\section{[H2] Adsorption, desorption and protection}

Decomposition of adsorbed OM is typically substantially slower than decomposition of the same type of OM in a freely suspended or dissolved state ${ }^{190}$, leading to the notion of 'sorptive protection' of OM. However, desorption can be facilitated by changes in $\mathrm{pH}$, electron availability, or by modifications to sorbent surfaces ${ }^{105}$. Indeed, evidence is mounting that plants are equipped with tools to achieve this exact purpose, such as the exudation of organic compounds designed to release bound organic matter from mineral surfaces ${ }^{191}$ and to adjust patterns of microbial community composition for optimal functionality ${ }^{192}$. With these developments in mind, we suggest that sorptive protection should be re-evaluated as an explanation for organic matter persistence, especially in systems inhabited by plant roots.

More broadly, the idea that there is reduced bioavailability of adsorbed substrates must be further scrutinized. Potentially, it is not that the adsorption process exerts overwhelming bonding forces, preventing breakdown of sorbates. Instead, adsorption could temporarily fix the location of an adsorbed substrate within a given pore network. Such localization would force the decomposer community to overcome the resulting spatial complexity of substrate locations, slowing the rate of decomposition ${ }^{187,193}$. To understand the relationship between OM persistence, bioavailability, and adsorption, enzyme activity experiments should be moved away from traditional batch experiments conducted with phases dispersed in a slurry. Instead, investigations must consider and preserve the three-dimensional microstructure of natural mineral-organic interfaces 46,194 .

Although the importance of various physicochemical variables in determining the magnitude of OM adsorption to select phyllosilicates, metal oxides and carbonates are well understood, the 
influence of these variables on the rates of adsorption and desorption is not. In addition, most OM sorption and desorption kinetic studies have been conducted on clean minerals exposed to aqueous phase OM. The kinetics of sorption onto realistic soils and sediments, where the newly offered adsorbate could compete with and actually induce the release of previously adsorbed organic compounds, have been studied on rare occasions ${ }^{86}$, presumably because of the difficulty in unequivocally attributing resulting observations to certain mechanisms when the sorbent is complex ${ }^{195}$.

\section{[H2] Adsorption as a framework-stabilizing process}

In addition to localizing the adsorbed substrate within a pore network, adsorption has the potential to significantly influence the stability of this network, thus influencing the microbial dynamics outlined above ${ }^{196}$. For example, investigations of sediment dynamics demonstrate that fine-grained minerals and mineral-OM assemblages have a controlling influence on the cohesive nature of sediment. Detailed understanding of the relevant relationships, unfortunately, remains elusive due to complexity of interparticle interactions in assemblages of fine-grained minerals. Even in the absence of OM, colloidal interactions [G] involve a variety of interaction mechanisms with different sensitivities to distance and particle shape and charge, such that different interactions to predominate in different systems ${ }^{197-199}$. In particular, for layered minerals, the combination of a long-range osmotic repulsion and a long-ranged attraction due to configurational entropy enables the formation of extensive aggregates with relatively dilute yet cohesive gel-like structures ${ }^{200,201202,203}$.

In the presence of OM, the stability of the mineral framework is further stabilized ${ }^{196}$. One conceptual model that could shed light into this stabilization is that the interaction of OM with mineral surfaces, at the OM abundances that exist in most soils and sediments, should be somewhat analogous to a wetting phenomenon. This analogy to wetting, in particular, is qualitatively consistent with the existence of either patchy or uniform distributions of OM in different systems ${ }^{16,204-206}$ (although patchy distributions can partly reflect microbial lifestyles ${ }^{207,208}$, they are also observed in studies examining the uptake of dissolved organic matter on pristine mineral surfaces in abiotic conditions as well as in soils ${ }^{135,209}$ ), with observations of preferential uptake of OM on rough surfaces or in colloidal aggregates ${ }^{79,207}$, and with the tendency of OM to induce lasting mineral aggregation ${ }^{94,96,210}$. It also is consistent with the hydrophobic character of the siloxane surface of phyllosilicate minerals in the absence of surface charge ${ }^{211,212}$ or even, in the case of smectite, in uncharged surface patches resulting from the non-uniform distribution of isomorphic substitutions ${ }^{62,67}$. In the case of oxides, studies indicating $\mathrm{OM}$ fractionation during uptake by $\mathrm{Fe}$ oxides suggest that the uptake of an initial 'contact layer' plays an important role in enabling mineral wetting by $\mathrm{OM}^{76}$. A number of other concepts developed in studies of wetting phenomena could prove useful in studies of mineralOM interactions, including theoretical representations of contact angles and thin films ${ }^{213-215}$ and descriptions of the impacts of biosurfactants on microorganism distribution, carbon cycling, and bioremediation $^{45,216,217}$. 


\section{[H2] Mineral-catalyzed polymerization}

There is substantial interest in the ability of minerals to both induce molecular growth (such as polymerization and large molecule formation) and contribute to molecular fragmentation, as it has implications for the global carbon cycle ${ }^{218,219}$ and in prebiotic chemistry ${ }^{220}$. The fundamental ability of minerals to modify organic compounds has been confirmed in laboratory settings ${ }^{220-222}$, but the catalytic synthesis of novel organic compounds has not yet been observed in the environment. To investigate this phenomenon, observations need to occur simultaneously on extremely small spatial scales but on very long time scales, invoking serious experimental challenges. In the environment, mineral-catalyzed synthesis could occur but could be counterbalanced by mineral catalysed disassembly as soon as the newly made product diffuses away from its compartment of origin. Moreover, the same type of mineral can assume opposite functions in the microbial conversion of adsorbed substrates ${ }^{223}$. Directing greater research effort at the quantitative relevance of these phenomena in natural systems would be particularly useful to settle the ongoing debate regarding the importance of mineral-induced catalysis in the environment.

\section{[H2] Redox and ROS}

In direct opposition to the expectation that minerals act as stable repositories for OM, the close association of mineral and organic compounds also enables electron transfer and coupled redox reactions. It is now well established that a plethora of microbial taxa and biochemical pathways couple the decomposition of organic matter to the oxidative or reductive transformation of minerals. Yet, despite tremendous progress in understanding the biogeochemical underpinnings of mineral-dependent life, the taxonomy of, enzymatic machinery employed by, and ecological controls on mineral-transforming microbes remain active and essential areas of inquiry. Importantly, the thermodynamic and kinetic constraints on operative metabolisms within natural soils and sediments remain poorly constrained, and yet are essential components for the efficacy of qualitative and quantitative biogeochemical models.

Further, despite some direct and indirect evidence of abiotic reactions mediating carbon transformation and mineralization at mineral surfaces, investigations of these interactions are sparse and, for those that have been conducted, conclusions are often based on correlations and/or anecdotal evidence. Moving forward, systematic and targeted investigations specifically linking OM cycling with direct and indirect reactions at mineral surfaces is needed. These investigations will undoubtedly require new methods and approaches to specifically probe the OM-mineral interface and track reaction products, such as incorporation of isotope labels and/or utilization of sophisticated imaging and spectroscopic techniques.

Acquisition of a clearer understanding of ROS-mediated carbon decomposition in soils and sediments has been hindered by several obstacles, including the difficulty in measuring shortlived ROS and identifying the fate of ROS among the numerous potential decay pathways within complex matrices. In fact, OM competes with numerous other ROS sinks, such as metals, 
chloride, bromide, or carbonates ${ }^{165,170,224}$, and thus the contribution of ROS to OM cycling will undoubtedly vary with local geochemical conditions, and between freshwater and marine systems. Further the promiscuity of ROS such as $\mathrm{O}_{2}{ }^{-{ }^{-}}$and $\mathrm{H}_{2} \mathrm{O}_{2}$ to act as both reductants and oxidants depending on the reactants and aqueous conditions leads to complex reaction networks even within relatively simple systems. Investigations of dityrosine formation within marine waters recently highlighted the potential for ROS-induced polymerization as a means to generate less bioavailable "humic"-like fluorescent DOM in the ocean ${ }^{225}$, indicating that ROS can mediate polymerization in addition to carbon mineralization. Thus, given the emerging recognition of minerals as sources of high ROS fluxes within the subsurface and the well-known role of ROS in organic carbon transformations, mineral-based ROS serve as a new frontier in understanding the carbon cycle.

Disentangling the complex network of mineral-based redox reactions is a necessary next step to understanding the controls on carbon processing and availability within soils and sediments. These reactions will likely be most relevant at redox interfaces and in fluctuating redox environments. Under these conditions, fresh precipitates free of significant surface coatings and prior to ripening will have increased surface reactivity. Further, (re)generation of mineral-bound and aqueous redox reactants will lead to new mineral reactive sites and (re)generation of ROS and other reactive intermediates (such as reactive DOM). Teasing out the relative contributions of light-dependent and -independent reactions on ROS formation and DOM decomposition is also required within sunlit environments. Thus, an improved understanding of $\mathrm{OM}$ cycling in soils and sediments also requires quantification of fluxes of solid-phase and aqueous reactants across light and redox gradients, likely requiring the use of spatially resolved techniques and thermodynamic and kinetic modeling to tease out the network of reactions at play.

\section{References}

1 Friedlingstein, P. et al. Global Carbon Budget 2019. Earth System Science Data 11, 1783-1838, doi:10.5194/essd-11-1783-2019 (2019).

2 Henin, S. \& Turc, L. in Transactions of the 4th International Congress of Soil Science. 4th International Congress of Soil Science. 152-154. (1950)

3 Kleber, M. et al. in Advances in Agronomy, Vol 130 Vol. 130 Advances in Agronomy (ed D. L. Sparks) 1-140 (2015).

4 Jacks, G. V. The biological nature of soil productivity. Soils and Fertilizers 26, 147-150 (1963).

$5 \quad$ Carson, R. Silent Spring. (Houghton Mifflin Company, 1962).

6 Stone, A. T. \& Morgan, J. J. Reduction and sisolution of manganese (III) and manganese (IV) oxides by organics. 1. Reaction with hydroquinone. Environmental Science \& Technology 18, 450-456, doi:10.1021/es00124a011 (1984).

7 Stone, A. T. \& Morgan, J. J. Reduction and dissolution of manganese (III) and manganese (IV) oxides by organics. 2. Survey of the reactivity of organics. Environmental Science \& Technology 18, 617-624, doi:10.1021/es00126a010 (1984). 
McBride, M. B. Reactivity of adsorbed and structural iron in hectorite as indicated by oxidation of benzidine. Clays and Clay Minerals 27, 224-230, doi:10.1346/ccmn.1979.0270308 (1979).

9 Parton, W. J., Schimel, D. S., Cole, C. V. \& Ojima, D. S. Analysis of factors controlling soil organic matter levels in Great Plains grasslands. Soil Science Society of America Journal 51, 1173-1179 (1987).

10 Oades, J. M. The retention of organic matter in soils. Biogeochemistry. 5 35-70 (1988). Jardine, P. M., Weber, N. L. \& McCarthy, J. F. Mechanisms of dissolved organic carbon adsorption on soil. Soil Science Society of America Journal 53, 1378-1385 (1989).

12 Gu, B., Schmitt, J., Chen, Z., Liang, L. \& McCarthy, J. F. Adsorption and desorption of natural organic matter on iron oxide: mechanisms and models. Environmental Science and Technology 28, 38-46 (1994).

13 Hedges, J. I. The formation and clay mineral reactions of melanoidins. Geochimica et Cosmochimica Acta 42, 69-76 (1978).

14 Rasmussen, C. et al. Beyond clay: towards an improved set of variables for predicting soil organic matter content. Biogeochemistry 137, 297-306, doi:10.1007/s10533-018-0424-3 (2018). Torn, M. S., Trumbore, S. E., Chadwick, O. A., Vitousek, P. M. \& Hendricks, D. M. Mineral control of soil organic carbon storage and turnover. Nature 389, 170-173 (1997).

Chenu, C. \& Plante, A. F. Clay-sized organo-mineral complexes in a cultivation chronosequence: revisiting the concept of the 'primary organo-mineral complex'. European Journal of Soil Science 57, 596-607, doi:10.1111/j.1365-2389.2006.00834.x (2006).

Baveye, P. C. et al. Emergent Properties of Microbial Activity in Heterogeneous Soil Microenvironments: Different Research Approaches Are Slowly Converging, Yet Major Challenges Remain. Frontiers in Microbiology 9, doi:10.3389/fmicb.2018.01929 (2018). Oades, J. M. in Minerals in soil environments. Second Edition. Vol. Book Serie Nr.1 (eds J. B. Dixon \& S. B. Weed) 89-160 (SSSA, 1989).

Batjes, N. H. Total carbon and nitrogen in the soils of the world. European Journal of Soil Science 47, 151-163 (1996). Jobbagy, E. G. \& Jackson, R. B. The vertical distribution of soil organic carbon and its relation to climate and vegetation. Ecological Applications 10, 423-436 (2000).

Vereecken, H., Maes, J., Feyen, J. \& Darius, P. ESTIMATING THE SOIL-MOISTURE RETENTION CHARACTERISTIC FROM TEXTURE, BULK-DENSITY, AND CARBON CONTENT. Soil Science 148, 389403, doi:10.1097/00010694-198912000-00001 (1989).

Sposito, G. The Chemistry of Soils. Third Edition edn, (Oxford University Press, 2016).

Ball, P. Water is an active matrix of life for cell and molecular biology. Proceedings of the National Academy of Sciences of the United States of America 114, 13327-13335, doi:10.1073/pnas.1703781114 (2017).

24 Schimel, J. et al. in 19th World Congress of Soil Science, Soil Solutions for a Changing World. 5558. Meysman, F. J. R., Middelburg, J. J. \& Heip, C. H. R. Bioturbation: a fresh look at Darwin's last idea. Trends in Ecology \& Evolution 21, 688-695, doi:10.1016/j.tree.2006.08.002 (2006). Miller, S. L. A production of amino acids under possible primitive earth conditions. Science 117, 528-529 (1953).

Heck, P. R. et al. The fall, recovery, classification, and initial characterization of the Hamburg, Michigan H4 chondrite. Meteorit. Planet. Sci., 19, doi:10.1111/maps.13584. Lengeler, J. W., Drews, G. \& Schlegel, H. G. Biology of the Prokaryotes. 984 (Wiley-Blackwell, 1999). 
Field, C. B., Behrenfeld, M. J., Randerson, J. T. \& Falkowski, P. Primary production of the biosphere: Integrating terrestrial and oceanic components. Science 281, 237-240, doi:10.1126/science.281.5374.237 (1998).

30 Hedges, J. I. \& Oades, J. M. Comparative organic geochemistries of soils and marine sediments. Organic Geochemistry 27, 319-361 (1997).

31 Anslyn, E. V. \& Dougherty, D. A. Modern physical organic chemistry. (University Science Books, 2006).

32 Fagel, N. in Developments in marine geology Ch. Chapter 4, 139-184 (Elsevier, 2007). Ito, A. \& Wagai, R. Global distribution of clay-size minerals on land surface for biogeochemical and climatological studies. Scientific Data 4, doi:10.1038/sdata.2017.103 (2017). Barron, V. \& Torrent. in EMU Notes in Mineralogy Vol. 14 297-336 (2013). Schulthess, C. P. \& Sparks, D. L. A critical assessment of surface adsorption models. Soil Science Society of America Journal 52, 92-97, doi:10.2136/sssaj1988.03615995005200010016x (1988). Heil, D. \& Sposito, G. Organic matter role in illitic soil colloids flocculation. 2. Surface charge. Soil Science Society of America Journal 57, 1246-1253, doi:10.2136/sssaj1993.03615995005700050015x (1993).

Quirk, J. P. in Advances in Agronomy, Vol 53 Vol. 53 Advances in Agronomy (ed D. L. Sparks) 121183 (1994).

Brown, G. E. et al. Metal Oxides Surfaces and Their Interactions with Aqueous Solutions and Microbial Organisms. Chemical Reviews 99, 77-174 (1999).

Armanious, A., Aeppli, M. \& Sander, M. Dissolved Organic Matter Adsorption to Model Surfaces: Adlayer Formation, Properties, and Dynamics at the Nanoscale. Environmental Science \& Technology 48, 9420-9429, doi:10.1021/es5026917 (2014).

Petridis, L. et al. Spatial Arrangement of Organic Compounds on a Model Mineral Surface: Implications for Soil Organic Matter Stabilization. Environmental Science \& Technology 48, 7984, doi:10.1021/es403430k (2014).

Sanderman, J., Maddern, T. \& Baldock, J. Similar composition but differential stability of mineral retained organic matter across four classes of clay minerals. Biogeochemistry 121, 409-424, doi:10.1007/s10533-014-0009-8 (2014).

Mueller, C. W. et al. Microscale soil structures foster organic matter stabilization in permafrost soils. Geoderma 293, 44-53, doi:10.1016/j.geoderma.2017.01.028 (2017).

Deen, W. M. Hindered transport of large molecules in liquid-filled pores. Aiche Journal 33, 14091425, doi:10.1002/aic.690330902 (1987).

McBride, M. B. Mobility of small molecules in interlayers of hectorite gels -ESR study with an uncharged spin-probe. Clays and Clay Minerals 42, 455-461, doi:10.1346/ccmn.1994.0420412 (1994).

Pignatello, J. J. \& Xing, B. S. Mechanisms of slow sorption of organic chemicals to natural particles. Environmental Science \& Technology 30, 1-11, doi:10.1021/es940683g (1996). Yang J.Q., Zhang X., Bourg I.C. \& Communications, S. H. A. N. 4D imaging reveals mechanisms of clay-carbon protection and release. Nature communications, in press (2021).

Navrotsky, A. Energetic clues to pathways to biomineralization: Precursors, clusters, and nanoparticles. Proceedings of the National Academy of Sciences of the United States of America 101, 12096-12101, doi:10.1073/pnas.0404778101 (2004).

4 Waychunas, G. A., Kim, C. S. \& Banfield, J. F. Nanoparticulate iron oxide minerals in soils and sediments: unique properties and contaminant scavenging mechanisms. Journal of Nanoparticle Research 7, 409-433, doi:10.1007/s11051-005-6931-x (2005). 

calculation and display of isolated and attached interfacial-energy minimizing particle shapes. Journal of Materials Science 47, 8290-8302, doi:10.1007/s10853-012-6739-x (2012).

50 Sposito, G. The Surface Chemistry of Natural Particles. (Oxford University Press, 2004).

51 Pauling, L. The structure of micas and related materials. Proc Natl Acad Sci U.S.A. 16, 123-129 (1930).

52 Chen, J. J. et al. Building two-dimensional materials one row at a time: Avoiding the nucleation barrier. Science 362, 1135-+, doi:10.1126/science.aau4146 (2018).

53 Venema, P., Hiemstra, T., Weidler, P. G. \& Van Riemsdijk, W. H. Intrinsic proton affinity of reactive surface groups of metal (hydr)oxides: Application to iron (hydr)oxides. J. Colloid Interf. Sci. 198, 282-295 (1998).

54 Sollins, P., Homann, P. \& Caldwell, B. A. Stabilization and destabilization of soil organic matter: Mechanisms and controls. Geoderma 74, 65-105 (1996).

55 Abramoff, R. et al. The Millennial model: in search of measurable pools and transformations for modeling soil carbon in the new century. Biogeochemistry 137, 51-71, doi:10.1007/s10533-0170409-7 (2018).

56 Blankinship, J. C., Becerra, C. A., Schaeffer, S. M. \& Schimel, J. P. Separating cellular metabolism from exoenzyme activity in soil organic matter decomposition. Soil Biology and Biochemistry 71, 68-75, doi:http://dx.doi.org/10.1016/j.soilbio.2014.01.010 (2014).

57 Chen, C., Hall, S. J., Coward, E. \& Thompson, A. Iron-mediated organic matter decomposition in humid soils can counteract protection. Nature communications 11, 1-13 (2020).

58 Leinemann, T. et al. Multiple exchange processes on mineral surfaces control the transport of dissolved organic matter through soil profiles. Soil Biology and Biochemistry 118, 79-90, doi:https://doi.org/10.1016/j.soilbio.2017.12.006 (2018).

59 Newcomb, C. J., Qafoku, N. P., Grate, J. W., Bailey, V. L. \& De Yoreo, J. J. Developing a molecular picture of soil organic matter-mineral interactions by quantifying organo-mineral binding. Nature communications 8, 1-8 (2017).

60 Ding, Y. et al. Chemodiversity of Soil Dissolved Organic Matter. Environmental Science \& Technology 54, 6174-6184, doi:10.1021/acs.est.0c01136 (2020).

61 Kellerman, A. M. et al. Unifying Concepts Linking Dissolved Organic Matter Composition to Persistence in Aquatic Ecosystems. Environmental Science \& Technology 52, 2538-2548, doi:10.1021/acs.est.7b05513 (2018).

62 Teppen, B. J. \& Aggarwal, V. Thermodynamics of organic cation exchange selectivity in smectites. Clays and Clay Minerals 55, 119-130, doi:10.1346/ccmn.2007.0550201 (2007).

63 Mackay, A. A. \& Vasudevan, D. Polyfunctional lonogenic Compound Sorption: Challenges and New Approaches To Advance Predictive Models. Environmental Science \& Technology 46, 92099223, doi:10.1021/es301036t (2012).

$64 \mathrm{Ni}, \mathrm{J}$. \& Pignatello, J. J. Charge-assisted hydrogen bonding as a cohesive force in soil organic matter: water solubility enhancement by addition of simple carboxylic acids. Environmental Science: Processes \& Impacts 20, 1225-1233 (2018).

65 Schwartzenbach, R. P., Gschwend, P. M. \& Imboden, D. M. Environmental Organic Chemistry. 1024 (Wiley, 2016).

66 Sposito, G., Skiper, N. T., Sutton, R., Park, S.-H., Soper, A. K. Greathouse, J. A. Surface geochemistry of the clay minerals. Proceedings of the National Academy of Sciences USA 96, 3358-3364 (1999).

67 Willemsen, J. A. R., Myneni, S. C. B. \& Bourg, I. C. Molecular Dynamics Simulations of the Adsorption of Phthalate Esters on Smectite Clay Surfaces. Journal of Physical Chemistry C 123, 13624-13636, doi:10.1021/acs.jpcc.9b01864 (2019). 
Wershaw, R. L. Model for Humus in Soils and Sediments. Envionmental Science and Technology 27, 814-816 (1993).

69 Kleber, M., Sollins, P. \& Sutton, R. A conceptual model of organo-mineral interactions in soils: self-assembly of organic molecular fragments into zonal structures on mineral surfaces. Biogeochemistry 85, 9-24 (2007).

70 Huang, X. Z. et al. Direct evidence for thickening nanoscale organic films at soil biogeochemical interfaces and its relevance to organic matter preservation. Environmental Science-Nano 7, 2747-2758, doi:10.1039/d0en00489h (2020).

71 Ohno, T. \& Kubicki, J. D. Adsorption of Organic Acids and Phosphate to an Iron (Oxyhydr)oxide Mineral: A Combined Experimental and Density Functional Theory Study. Journal of Physical Chemistry A 124, 3249-3260, doi:10.1021/acs.jpca.9b12044 (2020).

72 Bowden, J. W., Posner, A. M. \& Quirk, J. P. Ionic adsorption on variable charge mineral surfaces. Theoretical charge development and titration curves. Soil Research 15, 121-136 (1977). Riedel, T., Biester, H. \& Dittmar, T. Molecular Fractionation of Dissolved Organic Matter with Metal Salts. Environmental Science \& Technology 46, 4419-4426, doi:10.1021/es203901u (2012).

74 Possinger, A. R. et al. Organo-organic and organo-mineral interfaces in soil at the nanometer scale. Nature communications 11 (2020).

75 Mitchell, P. J., Simpson, A. J., Soong, R. \& Simpson, M. J. Nuclear Magnetic Resonance Analysis of Changes in Dissolved Organic Matter Composition with Successive Layering on Clay Mineral Surfaces. Soils 2, 8 (2018).

76 Coward, E. K., Ohno, T. \& Sparks, D. L. Direct Evidence for Temporal Molecular Fractionation of Dissolved Organic Matter at the Iron Oxyhydroxide Interface. Environmental Science \& Technology 53, 642-650, doi:10.1021/acs.est.8b04687 (2019).

77 Hatton, P.-J., Remusat, L., Zeller, B., Brewer, E. A. \& Derrien, D. NanoSIMS investigation of glycine-derived $\mathrm{C}$ and $\mathrm{N}$ retention with soil organo-mineral associations. Biogeochemistry 125, 303-313, doi:10.1007/s10533-015-0138-8 (2015).

78 Lehmann, J. et al. Spatial complexity of soil organic matter forms at nanometre scales. Nature Geoscience 1, 238-242, doi:10.1038/ngeo155 (2008).

79 Vogel, C. et al. Submicron structures provide preferential spots for carbon and nitrogen sequestration in soils. Nature Communications 5, doi:10.1038/ncomms3947 (2014).

80 Shaker, A., Komy, Z., Heggy, S. \& Elsayed, M. Kinetic Study for Adsorption Humic Acid on Soil Minerals. The journal of physical chemistry. A 116, doi:10.1021/jp3078826 (2012).

81 Koopal, L., Tan, W. F. \& Avena, M. Mixed ad/desorption kinetics unraveled with the equilibrium adsorption isotherm. Colloids and Surfaces a-Physicochemical and Engineering Aspects 577, 709722, doi:10.1016/j.colsurfa.2019.06.033 (2019).

82 Avena, M. J. \& Wilkinson, K. J. Disaggregation kinetics of a peat humic acid: Mechanism and pH effects. Environmental Science \& Technology 36, 5100-5105, doi:10.1021/es025582u (2002).

$83 \mathrm{Li}, \mathrm{W}$. L. et al. Real-time evaluation of natural organic matter deposition processes onto model environmental surfaces. Water Res. 129, 231-239, doi:10.1016/j.watres.2017.11.024 (2018).

84 Avena, M. J. \& Koopal, L. K. Kinetics of humic acid adsorption at solid-water interfaces. Environmental Science \& Technology 33, 2739-2744, doi:10.1021/es981236u (1999).

85 Lee, S. S., Fenter, P., Park, C. \& Nagy, K. L. Fulvic acid sorption on muscovite mica as a function of $\mathrm{pH}$ and time using in situ X-ray reflectivity. Langmuir 24, 7817-7829, doi:10.1021/la703456t (2008).

86 Lilienfein, J., Qualls, R. G., Uselman, S. M. \& Bridgham, S. D. Adsorption of dissolved organic carbon and nitrogen in soils of a weathering chronosequence. Soil Science Society of America Journal 68, 292-305 (2004). 
87 Mostovaya, A., Hawkes, J. A., Dittmar, T. \& Tranvik, L. J. Molecular Determinants of Dissolved Organic Matter Reactivity in Lake Water. Frontiers in Earth Science 5, doi:10.3389/feart.2017.00106 (2017).

88 Chacon, S. S. et al. Mineral Surfaces as Agents of Environmental Proteolysis: Mechanisms and Controls. Environmental Science \& Technology, doi:10.1021/acs.est.8b05583 (2019).

89 Haas, K. L. \& Franz, K. J. Application of Metal Coordination Chemistry To Explore and Manipulate Cell Biology. Chemical Reviews 109, 4921-4960, doi:10.1021/cr900134a (2009).

90 Christl, I. \& Kretzschmar, R. C-1s NEXAFS spectroscopy reveals chemical fractionation of humic acid by cation-induced coagulation. Environmental Science \& Technology 41, 1915-1920, doi:10.1021/es062141s (2007).

91 Edwards, D. C. \& Myneni, S. C. B. Hard and soft X-ray absorption spectroscopic investigation of aqueous Fe(III)-hydroxamate siderophore complexes. Journal of Physical Chemistry A 109, 10249-10256, doi:10.1021/jp053349n (2005).

92 Radke, C. J. Gibbs adsorption equation for planar fluid-fluid interfaces: Invariant formalism. Advances in Colloid and Interface Science 222, 600-614, doi:10.1016/j.cis.2014.01.001 (2015).

93 Schwertmann, U. Inhibitory effect of soil organic matter on crystallization of amorphous ferric hydroxide. Nature 212, 645-+, doi:10.1038/212645b0 (1966).

94 Eusterhues, K. et al. Characterization of Ferrihydrite-Soil Organic Matter Coprecipitates by X-ray Diffraction and Mossbauer Spectroscopy. Environmental Science \& Technology 42, 7891-7897, doi:10.1021/es800881w (2008).

95 Levard, C. et al. Structure and distribution of allophanes, imogolite and proto-imogolite in volcanic soils. Geoderma 183, 100-108, doi:10.1016/j.geoderma.2012.03.015 (2012).

96 Chen, C. M., Kukkadapu, R. \& Sparks, D. L. Influence of Coprecipitated Organic Matter on Fe(aq)(2+)-Catalyzed Transformation of Ferrihydrite: Implications for Carbon Dynamics. Environmental Science \& Technology 49, 10927-10936, doi:10.1021/acs.est.5b02448 (2015).

97 Kaiser, K. \& Zech, W. Release of natural organic matter sorbed to oxides and a subsoil. Soil Science Society of America Journal 63, 1157-1166 (1999).

98 Oren, A. \& Chefetz, B. Sorptive and Desorptive Fractionation of Dissolved Organic Matter by Mineral Soil Matrices. J. Environ. Qual. 41, 526-533, doi:10.2134/jeq2011.0362 (2012).

99 Lippold, H. \& Lippmann-Pipke, J. Effect of humic matter on metal adsorption onto clay materials: Testing the linear additive model. Journal of Contaminant Hydrology 109, 40-48, doi:https://doi.org/10.1016/j.jconhyd.2009.07.009 (2009).

100 Eusterhues, K. et al. Reduction of ferrihydrite with adsorbed and coprecipitated organic matter: microbial reduction by Geobacter bremensis vs. abiotic reduction by Na-dithionite.

Biogeosciences 11, 4953-4966, doi:10.5194/bg-11-4953-2014 (2014).

101 Eusterhues, K., Rumpel, C., Kleber, M. \& Kogel-Knabner, I. Stabilisation of soil organic matter by interactions with minerals as revealed by mineral dissolution and oxidative degradation. Organic Geochemistry 34, 1591-1600 (2003).

102 Grybos, M., Davranche, M., Gruau, G. \& Petitjean, P. Is trace metal release in wetland soils controlled by organic matter mobility or Fe-oxyhydroxides reduction? Journal of Colloid and Interface Science 314, 490-501, doi:10.1016/j.jcis.2007.04.062 (2007).

103 Pan, W., Kan, J., Inamdar, S., Chen, C. \& Sparks, D. Dissimilatory microbial iron reduction release DOC (dissolved organic carbon) from carbon-ferrihydrite association. Soil Biology and Biochemistry 103, 232-240, doi:10.1016/j.soilbio.2016.08.026 (2016).

104 Poggenburg, C., Mikutta, R., Schippers, A., Dohrmann, R. \& Guggenberger, G. Impact of natural organic matter coatings on the microbial reduction of iron oxides. Geochimica et Cosmochimica Acta 224, 223-248, doi:https://doi.org/10.1016/i.gca.2018.01.004 (2018). 
105 Thompson, A., Chadwick, O. A., Boman, S. \& Chorover, J. Colloid mobilization during soil iron redox oscillations. Environmental Science \& Technology 40, 5743-5749 (2006).

106 Collignon, C., Ranger, J. \& Turpault, M. P. Seasonal dynamics of Al- and Fe-bearing secondary minerals in an acid forest soil: influence of Norway spruce roots (Picea abies (L.) Karst.). European Journal of Soil Science 63, 592-602, doi:10.1111/j.1365-2389.2012.01470.x (2012).

107 Ochs, M., Brunner, I., Stumm, W. \& Cosovic, B. Effect of root exudates and humic substances on weathering kinetics. Water Air and Soil Pollution 68, 213-229, doi:10.1007/bf00479404 (1993).

108 Fang, L., Cao, Y., Huang, Q., Walker, S. L. \& Cai, P. Reactions between bacterial exopolymers and goethite: A combined macroscopic and spectroscopic investigation. Water Res. 46, 5613-5620, doi:http://dx.doi.org/10.1016/j.watres.2012.07.046 (2012).

109 Goyne, K. W., Chorover, J., Zimmerman, A. R., Komarneni, S. \& Brantley, S. L. Influence of mesoporosity on the sorption of 2,4-dichlorophenoxyacetic acid onto alumina and silica. $J$. Colloid Interf. Sci. 272, 10-20 (2004).

110 Johnston, C. T., Premachandra, G. S., Szabo, T., Lok, J. \& Schoonheydt, R. A. Interaction of Biological Molecules with Clay Minerals: A Combined Spectroscopic and Sorption Study of Lysozyme on Saponite. Langmuir 28, 611-619, doi:10.1021/la203161n (2012).

111 Hunter, W. R. et al. Metabolism of mineral-sorbed organic matter and microbial lifestyles in fluvial ecosystems. Geophysical Research Letters 43, 1582-1588, doi:10.1002/2016gl067719 (2016).

112 McGhee, I., Sannino, F., Gianfreda, L. \& Burns, R. G. Bioavailability of 2,4-D sorbed to a chloritelike complex. Chemosphere 39, 285-291, doi:10.1016/s0045-6535(99)00109-5 (1999).

113 Keiluweit, M. et al. Long-term litter decomposition controlled by manganese redox cycling. Proceedings of the National Academy of Sciences, 201508945 (2015).

114 Kallenbach, C. M., Frey, S. D. \& Grandy, A. S. Direct evidence for microbial-derived soil organic matter formation and its ecophysiological controls. Nature Communications 7 , doi:10.1038/ncomms13630 (2016).

115 Malik, A. \& Gleixner, G. Importance of microbial soil organic matter processing in dissolved organic carbon production. Fems Microbiology Ecology 86, 139-148, doi:10.1111/15746941.12182 (2013).

116 Simpson, A., J., Simpson, M. J., Smith, E. \& Kelleher, B. P. Microbially Derived Inputs to Soil Organic Matter: Are Current Estimates Too Low? Environmental Science \& Technology 41, 80708076 (2007).

117 Ferris, J. P. Montmorillonite catalysis of 30-50 mer oligonucleotides: Laboratory demonstration of potential steps in the origin of the RNA world. Origins of Life and Evolution of the Biosphere 32, 311-332, doi:10.1023/a:1020543312109 (2002).

118 Aldersley, M. F., Joshi, P. C., Price, J. D. \& Ferris, J. P. The role of montmorillonite in its catalysis of RNA synthesis. Applied Clay Science 54, 1-14, doi:10.1016/j.clay.2011.06.011 (2011).

119 Duval, S. et al. On the why's and how's of clay minerals' importance in life's emergence. Applied Clay Science 195, doi:10.1016/j.clay.2020.105737 (2020).

120 Laszlo, P. Chemical reactions on clays. Science 235, 1473-1477, doi:10.1126/science.235.4795.1473 (1987).

121 McBride, M. B. Adsorption and oxidation of phenolic compounds by iron and manganese oxides Soil Science Society of America Journal 51, 1466-1472 (1987).

122 Sheng, F. et al. Rapid Hydrolysis of Penicillin Antibiotics Mediated by Adsorbed Zinc on Goethite Surfaces. Environmental Science \& Technology 53, 10705-10713, doi:10.1021/acs.est.9b02666 (2019).

123 Chorover, J. \& Amistadi, M. K. Reaction of forest floor organic matter at goethite, birnessite and smectite surfaces. Geochimica et Cosmochimica Acta 65, 95-109 (2001). 
124 Faure, P., Schlepp, L., Burkle-Vitzthum, V. \& Elie, M. Low temperature air oxidation of n-alkanes in the presence of Na-smectite. Fuel 82, 1751-1762, doi:10.1016/s0016-2361(03)00133-9 (2003).

125 Mitchell, P. J. et al. Solution-state NMR investigation of the sorptive fractionation of dissolved organic matter by alkaline mineral soils. Environmental Chemistry 10, 333-340 (2013).

126 Riedel, T., Zak, D., Biester, H. \& Dittmar, T. Iron traps terrestrially derived dissolved organic matter at redox interfaces. Proceedings of the National Academy of Sciences of the United States of America 110, 10101-10105, doi:10.1073/pnas.1221487110 (2013).

127 Chacon, S. S., Garcia-Jaramillo, M., Liu, S. Y., Ahmed, M. \& Kleber, M. Differential capacity of kaolinite and birnessite to protect surface associated proteins against thermal degradation. Soil Biology \& Biochemistry 119, 101-109, doi:10.1016/j.soilbio.2018.01.020 (2018).

128 Reardon, P. N. et al. Abiotic Protein Fragmentation by Manganese Oxide: Implications for a Mechanism to Supply Soil Biota with Oligopeptides. Environmental Science \& Technology 50, 3486-3493, doi:10.1021/acs.est.5b04622 (2016).

129 Johnson, K. et al. Towards a mechanistic understanding of carbon stabilization in manganese oxides. Nature Comm. 6, 7628 (2015).

130 Cleaves, H. J. et al. Mineral-organic interfacial processes: potential roles in the origins of life. Chemical Society Reviews 41, 5502-5525, doi:10.1039/c2cs35112a (2012).

131 Soma, Y. \& Soma, M. CHEMICAL-REACTIONS OF ORGANIC-COMPOUNDS ON CLAY SURFACES. Environmental Health Perspectives 83, 205-214, doi:10.2307/3430656 (1989).

132 Norde, W. My voyage of discovery to proteins in flatland............ and beyond. Colloids and Surfaces B-Biointerfaces 61, 1-9, doi:10.1016/j.colsurfb.2007.09.029 (2008).

133 Hoarau, M., Badieyan, S. \& Marsh, E. N. G. Immobilized enzymes: understanding enzyme surface interactions at the molecular level. Organic \& Biomolecular Chemistry 15, 9539-9551, doi:10.1039/c7ob01880k (2017).

134 Maurice, P. A. \& Namjesnik-Dejanovic, K. Aggregate structures of sorbed humic substances observed in aqueous solution. Environmental Science and Technology 33, 1538-1541 (1999).

135 Myneni, S. C. B., Brown, J. T., Martinez, G. A., Meyer-Ilse, W.,. Imaging of humic substance macromolecular structures in water and soils. Science 286, 1335-1337 (1999).

136 Denton, J. K. et al. Molecular-level origin of the carboxylate head group response to divalent metal ion complexation at the air-water interface. Proceedings of the National Academy of Sciences of the United States of America 116, 14874-14880, doi:10.1073/pnas.1818600116 (2019).

137 Liu, W., Tkatchenko, A. \& Scheffler, M. Modeling Adsorption and Reactions of Organic Molecules at Metal Surfaces. Accounts of Chemical Research 47, 3369-3377, doi:10.1021/ar500118y (2014).

138 Nealson, K. H. \& Saffarini, D. Iron and manganese in anaerobic respiration: Environmental significance, physiology, and regulation. Annu. Rev. Microbiol. 48, 311-343 (1994).

139 Shi, L. et al. Extracellular electron transfer mechanisms between microorganisms and minerals. Nature Rev. Microbiol. 14, 651-662 (2016).

140 Gorby, Y. A. et al. Electrically conductive bacterial nanowires produced by Shewanella oneidensis strain MR-1 and other microorganisms. Proc. Nation. Acad. Sci. 103, 11358-11363 (2006).

141 Reguera, G. et al. Extracellular electron transfer via microbial nanowires. Nature 435, 10981101, doi:10.1038/nature03661 (2005).

142 Marsili, E. et al. Shewanella Secretes flavins that mediate extracellular electron transfer. Proceedings of the National Academy of Sciences of the United States of America 105, 39683973, doi:10.1073/pnas.0710525105 (2008).

143 Remucal, C. K. \& Ginder-Vogel, M. A critical review of the reactivity of manganese oxides with organic contaminants. Environ. Sci.: Processes Impacts 16, 1247 (2014). 
144 Sunda, W. G. \& Kieber, D. J. Oxidation of humic substances by manganese oxides yields lowmolecular weight organic substrates. Nature 367, 62-64, doi:10.1038/367062a0 (1994).

145 Ma, D., Wu, J., Yang, P. \& Zhu, M. Q. Coupled Manganese Redox Cycling and Organic Carbon Degradation on Mineral Surfaces. Environmental Science \& Technology 54, 8801-8810, doi:10.1021/acs.est.0c02065 (2020).

146 Russo, F., Johnson, C. J., McKenzie, D., Aiken, J. M. \& Pedersen, J. A. Pathogenic prion protein is degraded by a manganese oxide mineral found in soils. Journal of General Virology 90, 275-280, doi:10.1099/vir.0.003251-0 (2009).

147 Heckman, K., Vazquez-Ortega, A., Gao, X. D., Chorover, J. \& Rasmussen, C. Changes in water extractable organic matter during incubation of forest floor material in the presence of quartz, goethite and gibbsite surfaces. Geochimica et Cosmochimica Acta 75, 4295-4309, doi:10.1016/j.gca.2011.05.009 (2011).

148 Lehmann, R. G., Cheng, H. H. \& Harsh, J. B. Oxidation of phenolic acids by soil iron and manganese oxides. Soil Sci. Soc. Am. J. 51, 352-356 (1987).

149 Stuckey, J. W. et al. Impacts of hydrous manganese oxide on the retention and lability of dissolved organic matter. Geochem. Trans. 19, 6 (2018).

150 Suter, D., Banwart, S. \& Stumm, W. Dissolution of hydrous iron(III) oxides byb reductive mechanisms. Langmuir 7, 809-813, doi:10.1021/la00052a033 (1991).

151 Jones, M. E. et al. Manganese-driven carbon oxidation at oxic-anoxic interfaces. Environ. Sci. Technol. 52, 12349-12357 (2018).

152 Estes, E. R., Andeer, P. F., Nordlund, D., Wankel, S. \& Hansel, C. M. Biogenic manganese oxides as reservoirs of organic carbon and proteins in terrestrial and marine environments. Geobiol. 15, 158-172 (2016).

153 Fridovich, I. Oxygen toxicity: A radical explanation. Journal of Experimental Biology 201, 12031209 (1998).

154 Trusiak, A., Treibergs, L. A., Kling, G. W. \& Cory, R. M. The role of iron and reactive oxygen species in the production of $\mathrm{CO} 2$ in arctic soil waters. Geochimica Et Cosmochimica Acta 224, 8095, doi:10.1016/j.gca.2017.12.022 (2018).

155 Hansel, C. M. \& Diaz, J. M. Reactive oxygen species production by marine biota. Annual Review of Marine Science. Annual Review of Marine Science, doi:doi:10.1146/annurev-marine-041320102550 (2021).

156 Blough, N. V. \& Zepp, R. G. in Active Oxygen in Chemistry (eds C.S. Foote, J.S. Valentine, A. Greenburg, \& J.F. Liebman) 280-333 (1995).

$157 \mathrm{Xu}, \mathrm{X}$. et al. Chraracteristics of desert varnish from nanometer to micrometer scale: A photooxidation model of its formation. Chem. Geol. 522, 55-70, doi:10.1016/j.chemgeo.2019.05.016 (2019).

158 Schoonen, M. A. A. et al. in The Emergent Field of Medical Mineralogy and Geochemistry Vol. 64 (eds N. Sahia, M.A.A. Schoonen, \& H.C.W. Skinner) 59-113 (Geochemical Society, 2006).

159 Georgiou, C. D. et al. Evidence for photochemical production of reactive oxygen species in desert soils. Nature Comm. 6, 7100, doi:10.1038/ncomms8100 (2015).

160 Gil-Lozano, C., Davila, A. F., Losa-Adams, E., Fairen, A. G. \& Gago-Duport, L. Quantifying Fenton reaction pathways driven by self-generated $\mathrm{H}_{2} \mathrm{O}_{2}$ on pyrite surfaces. Scientific Reports 7, 43703 (2017).

161 Tong, M. et al. Production of Abundant Hydroxyl Radicals from Oxygenation of Subsurface Sediments. Environmental Science \& Technology 50, 214-221, doi:10.1021/acs.est.5b04323 (2016). 
162 Xu, J., Sahia, N., Eggleston, C. M. \& Schoonen, M. A. A. Reactive oxygen species at the oxide/water interface: Formation mechanisms and implications for prebiotic chemistry and the origin of life. EPSL 363, 156-167 (2013).

163 Yuan, X. et al. Production of hydrogen peroxide in groundwater at Rifle, Colorado. Environ. Sci. Technol. 51, 7881-7891 (2017).

164 Sutherland, K. M. et al. Spatial heterogeneity in particle associated, light-independent superoxide production within productive coastal waters. JGR - Oceans, In review (2020).

165 Page, S. E. et al. Dark Formation of Hydroxyl Radical in Arctic Soil and Surface Waters. Environmental Science \& Technology 47, 12860-12867, doi:10.1021/es4033265 (2013).

166 Rose, A. L. The influence of extracellular superoxide on iron redox chemistry and bioavailability to aquatic microorganisms. Frontiers in Microbiology 3, doi:10.3389/fmicb.2012.00124 (2012).

167 Waggoner, D. C., Wozniak, A. S., Cory, R. M. \& Hatcher, P. G. The role of reactive oxygen species in the degradation of lignin derived dissolved organic matter. Geochimica Et Cosmochimica Acta 208, 171-184, doi:10.1016/j.gca.2017.03.036 (2017).

168 Goldstone, J. V. \& Voelker, B. M. Chemistry of superoxide radical in seawater: CDOM associated sink of superoxide in coastal waters. Environmental Science \& Technology 34, 1043-1048, doi:10.1021/es9905445 (2000).

169 Voelker, B. M. \& Sulzberger, B. Effects of fulvic acid on Fe(II) oxidation by hydrogen peroxide. Environmental Science \& Technology 30, 1106-1114, doi:10.1021/es9502132 (1996).

170 Buxton, G. V., Greenstock, C. L., Helman, W. P. \& Ross, A. B. CRITICAL-REVIEW OF RATE CONSTANTS FOR REACTIONS OF HYDRATED ELECTRONS, HYDROGEN-ATOMS AND HYDROXYL RADICALS (.OH/.O-) IN AQUEOUS-SOLUTION. Journal of Physical and Chemical Reference Data 17, 513-886, doi:10.1063/1.555805 (1988).

171 Goldstone, J. V., Pullin, M. J., Bertilsson, S. \& Voelker, B. M. Reactions of hydroxyl radical with humic substances: Bleaching, mineralization, and production of bioavailable carbon substrates. Environ. Sci. Technol. 36, 364-372 (2002).

172 Pullin, M. J., Bertilsson, S., Goldstone, J. V. \& Voelker, B. M. Effects of sunlight and hydroxyl radical on dissolved organic matter: Bacterial growth efficiency and production of carboxylic acids and other substrates. Limnol. Oceanogr. 49, 2011-2022 (2014).

173 Wuttig, K., Heller, M. I. \& Croot, P. L. Pathways of Superoxide (O-2(-)) Decay in the Eastern Tropical North Atlantic. Environmental Science \& Technology 47, 10249-10256, doi:10.1021/es401658t (2013).

174 Heller, M. I., Wuttig, K. \& Croot, P. L. Identifying the Sources and Sinks of CDOM/FDOM across the Mauritanian Shelf and Their Potential Role in the Decomposition of Superoxide (O2-). Frontiers in Marine Science 3, doi:10.3389/fmars.2016.00132 (2016).

175 Scully, N. M., Cooper, W. J. \& Tranvik, L. J. Photochemical effects on microbial activity in natural waters: the interaction of reactive oxygen species and dissolved organic matter. Fems Microbiology Ecology 46, 353-357, doi:10.1016/s0168-6496(03)00198-3 (2003).

176 Hall, S. J. \& Silver, W. L. Iron oxidation stimulates organic matter decomposition in humid tropical forest soils. Global Change Biology 19, 2804-2813, doi:10.1111/gcb.12229 (2013).

177 Xiao, Y. H., Carena, L., Nasi, M. T. \& Vahatalo, A. V. Superoxide-driven autocatalytic dark production of hydroxyl radicals in the presence of complexes of natural dissolved organic matter and iron. Water Res. 177, doi:10.1016/j.watres.2020.115782 (2020).

178 Bach, C. E. et al. Measuring phenol oxidase and peroxidase activities with pyrogallol, L-DOPA, and ABTS: Effect of assay conditions and soil type. Soil Biology \& Biochemistry 67, 183-191, doi:10.1016/j.soilbio.2013.08.022 (2013).

179 Carson, J. K. et al. Low Pore Connectivity Increases Bacterial Diversity in Soil. Applied and Environmental Microbiology 76, 3936-3942, doi:10.1128/aem.03085-09 (2010). 
180 Negassa, W. C. et al. Properties of Soil Pore Space Regulate Pathways of Plant Residue Decomposition and Community Structure of Associated Bacteria. Plos One 10, doi:10.1371/journal.pone.0123999 (2015).

181 Miltner, A., Bombach, P., Schmidt-Brucken, B. \& Kastner, M. SOM genesis: microbial biomass as a significant source. Biogeochemistry 111, 41-55, doi:10.1007/s10533-011-9658-z (2012).

182 Angst, G., Mueller, K. E., Nierop, K. G. J. \& Simpson, M. J. Plant- or microbial-derived? A review on the molecular composition of stabilized soil organic matter. Soil Biology and Biochemistry, doi:https://doi.org/10.1016/j.soilbio.2021.108189 (2021).

183 Liang, C., Amelung, W., Lehmann, J. \& Kastner, M. Quantitative assessment of microbial necromass contribution to soil organic matter. Global Change Biology 25, 3578-3590, doi:10.1111/gcb.14781 (2019).

184 Young, I. M. \& Crawford, J. W. Interactions and self-organization in the soil-microbe complex. Science 304, 1634-1637 (2004).

185 Levin, S. A. Ecosystems and the biosphere as complex adaptive systems. Ecosystems 1, 431-436, doi:10.1007/s100219900037 (1998).

186 D'Souza, G. \& Kost, C. Experimental Evolution of Metabolic Dependency in Bacteria. Plos Genetics 12, doi:10.1371/journal.pgen.1006364 (2016).

187 Lehmann, J. et al. Persistence of soil organic carbon caused by functional complexity. Nature Geoscience 13, 529-534, doi:10.1038/s41561-020-0612-3 (2020).

188 Nunan, N., Schmidt, H. \& Raynaud, X. The ecology of heterogeneity: soil bacterial communities and C dynamics. Philosophical Transactions of the Royal Society B-Biological Sciences 375, doi:10.1098/rstb.2019.0249 (2020).

189 Wilhelm, R. C., Pepe-Ranney, C., Weisenhorn, P., Lipton, M. \& Buckley, D. H. Competitive Exclusion and Metabolic Dependency among Microorganisms Structure the Cellulose Economy of an Agricultural Soil. Mbio 12, doi:10.1128/mBio.03099-20 (2021).

190 Kalbitz, K., Schwesig, D., Rethemeyer, J. \& Matzner, E. Stabilization of dissolved organic matter by sorption to the mineral soil. Soil Biology \& Biochemistry 37, 1319-1331 (2005).

191 Keiluweit, M. et al. Mineral protection of soil carbon counteracted by root exudates. Nature Climate Change 5, 588-595 (2015).

192 Zhalnina, K. et al. Dynamic root exudate chemistry and microbial substrate preferences drive patterns in rhizosphere microbial community assembly. Nature Microbiology 3, 470-480, doi:10.1038/s41564-018-0129-3 (2018).

193 Woolf, D. \& Lehmann, J. Microbial models with minimal mineral protection can explain longterm soil organic carbon persistence. Scientific Reports 9, doi:10.1038/s41598-019-43026-8 (2019).

194 Borer, B., Tecon, R. \& Or, D. Spatial organization of bacterial populations in response to oxygen and carbon counter-gradients in pore networks. Nature Communications 9, doi:10.1038/s41467018-03187-y (2018).

195 Barzen-Hanson, K. A., Davis, S. E., Kleber, M. \& Field, J. A. Sorption of Fluorotelomer Sulfonates, Fluorotelomer Sulfonamido Betaines, and a Fluorotelomer Sulfonamido Amine in National Foam Aqueous Film-Forming Foam to Soil. Environmental Science \& Technology 51, 12394-12404, doi:10.1021/acs.est.7b03452 (2017).

196 Grabowski, R. C., Droppo, I. G. \& Wharton, G. Erodibility of cohesive sediment: The importance of sediment properties. Earth-Science Reviews 105, 101-120, doi:10.1016/j.earscirev.2011.01.008 (2011).

197 Israelachvili, J. \& Wennerstrom, H. Role of hydration and water structure in biological and colloidal interactions. Nature 379, 219-225, doi:10.1038/379219a0 (1996). 
Sushko, M. L. \& Rosso, K. M. The origin of facet selectivity and alignment in anatase TiO2 nanoparticles in electrolyte solutions: implications for oriented attachment in metal oxides. Nanoscale 8, 19714-19725, doi:10.1039/c6nr06953c (2016).

199 Shen, X. Y. \& Bourg, I. C. Molecular dynamics simulations of the colloidal interaction between smectite clay nanoparticles in liquid water. Journal of Colloid and Interface Science 584, 610-621, doi:10.1016/j.jcis.2020.10.029 (2021).

200 Michot, L. J. et al. Liquid-crystalline aqueous clay suspensions. Proceedings of the National Academy of Sciences of the United States of America 103, 16101-16104, doi:10.1073/pnas.0605201103 (2006).

201 Underwood, T. R. \& Bourg, I. C. Large-Scale Molecular Dynamics Simulation of the Dehydration of a Suspension of Smectite Clay Nanoparticles. Journal of Physical Chemistry C 124, 3702-3714, doi:10.1021/acs.jpcc.9b11197 (2020).

202 Pignon, F. et al. Yield stress thixotropic clay suspension: Investigation of structure by light, neutron, and x-ray scattering. Physical Review E 56, 3281-3289, doi:10.1103/PhysRevE.56.3281 (1997).

203 Bourg, I. C. \& Ajo-Franklin, J. B. Clay, Water, and Salt: Controls on the Permeability of FineGrained Sedimentary Rocks. Accounts of Chemical Research 50, 2067-2074, doi:10.1021/acs.accounts.7b00261 (2017).

204 Mayer, L. M. Surface area control of organic carbon accumulation in continental shelf sediments. Geochimica et Cosmochimica Acta 58, 1271-1284 (1994).

205 Ransom, B., Dongsom, K., Kastner, M. \& Wainwright, S. Organic matter preservation on continental slopes: Importance of mineralogy and surface area. Geochimica et Cosmochimica Acta 62, 1329-1345 (1998).

206 Kaiser, K. \& Guggenberger, G. Mineral surfaces and soil organic matter. European Journal of Soil Science 54, 219-236, doi:doi:10.1046/j.1365-2389.2003.00544.x (2003).

207 Barker, W. W., Welch, S. A., Chu, S. \& Banfield, J. F. Experimental observations of the effects of bacteria on aluminosilicate weathering. American Mineralogist 83, 1551-1563, doi:10.2138/am1998-11-1243 (1998).

208 Watteau, F. \& Villemin, G. Soil Microstructures Examined Through Transmission Electron Microscopy Reveal Soil-Microorganisms Interactions. Frontiers in Environmental Science 6, doi:10.3389/fenvs.2018.00106 (2018).

209 Namjesnik-Dejanovic, K. \& Maurice, P. A. Conformations and aggregate structures of sorbed natural organic matter on muscovite and hematite. Geochimica Et Cosmochimica Acta 65, 10471057, doi:10.1016/s0016-7037(00)00542-1 (2001).

210 Moreau, J. W. et al. Extracellular proteins limit the dispersal of biogenic nanoparticles. Science 316, 1600-1603, doi:10.1126/science.1141064 (2007).

211 Jaynes, W. F. \& Boyd, S. A. Hydrophobicity of siloxane surfaces in smectites as revealed by aromatic hydrocarbon adsorption from water. Clays and Clay Minerals 39, 428-436 (1991).

212 Rotenberg, B., Patel, A. J. \& Chandler, D. Molecular Explanation for Why Talc Surfaces Can Be Both Hydrophilic and Hydrophobic. Journal of the American Chemical Society 133, 20521-20527, doi:10.1021/ja208687a (2011).

213 Radke, C. J. \& Prausnitz, J. M. THERMODYNAMICS OF MULTI-SOLUTE ADSORPTION FROM DILUTE LIQUID SOLUTIONS. Aiche Journal 18, 761-+, doi:10.1002/aic.690180417 (1972).

214 Degennes, P. G. WETTING - STATICS AND DYNAMICS. Reviews of Modern Physics 57, 827-863, doi:10.1103/RevModPhys.57.827 (1985).

215 McGinley, P. M., Katz, L. E. \& Weber, W. J. A DISTRIBUTED REACTIVITY MODEL FOR SORPTION BY SOILS AND SEDIMENTS.2. MULTICOMPONENT SYSTEMS AND COMPETITIVE EFFECTS. Environmental Science \& Technology 27, 1524-1531, doi:10.1021/es00045a006 (1993). 
216 Davey, M. E., Caiazza, N. C. \& O'Toole, G. A. Rhamnolipid surfactant production affects biofilm architecture in Pseudomonas aeruginosa PAO1. J. Bacteriol. 185, 1027-1036, doi:10.1128/jb.185.3.1027-1036.2003 (2003).

217 Zhang, Y. M. \& Miller, R. M. ENHANCED OCTADECANE DISPERSION AND BIODEGRADATION BY A PSEUDOMONAS RHAMNOLIPID SURFACTANT (BIOSURFACTANT). Applied and Environmental Microbiology 58, 3276-3282, doi:10.1128/aem.58.10.3276-3282.1992 (1992).

218 Myneni, S. C. B. Chemistry of Natural Organic Matter-The Next Step: Commentary on a Humic Substances Debate. Journal of Environmental Quality 48, 233-235, doi:10.2134/jeq2019.02.0002c (2019).

219 Kleber, M. \& Lehmann, J. Humic Substances Extracted by Alkali Are Invalid Proxies for the Dynamics and Functions of Organic Matter in Terrestrial and Aquatic Ecosystems. Journal of Environmental Quality 48, 207-216, doi:10.2134/jeq2019.01.0036 (2019).

220 Hazen, R. M. \& Sverjensky, D. A. Mineral surfaces, geochemical complexities, and the origins of life. Cold Spring Harb. Perspect. Biol. 2, a002162 (2010).

221 Huang, P. M. \& Hardie, A. G. in Biophysico-Chemical Processes Involving Natural Nonliving Organic Matter in Environmental Systems (eds N. Senesi, B. Xing, \& Huang P. M.) 41-109 (John Wiley \& Sons, Inc., 2009).

222 Huang, P. M. \& Hardie, A. G. in Handbook of soil sciences: Properties and processes (eds P.M. Huang, Y. Li, \& M.E. Sumner) 18.11 - 18.40 (CRC Press, 2012).

223 Van Loosdrecht, M. C. M., Lyklema, J., Norde, W. \& Zehnder, A. J. B. Influence of interfaces on microbial activity Microbiological Reviews 54, 75-87 (1990).

224 Lipson, D. A., Jha, M., Raab, T. K. \& Oechel, W. C. Reduction of iron (III) and humic substances plays a major role in anaerobic respiration in an Arctic peat soil. Journal of Geophysical Research-Biogeosciences 115, doi:10.1029/2009jg001147 (2010).

225 Paerl, R. W., Claudio, I. M., Shields, M. R., Bianchi, T. S. \& Osburn, C. L. Dityrosine formation via reactive oxygen consumption yields increasingly recalcitrant humic-like fluorescent organic matter in the ocean. Limnology and Oceanography Letters 5, 337-345, doi:10.1002/lol2.10154 (2020).

226 Guggenheim, S. et al. Summary of recommendations of nomenclature committees relevant to clay mineralogy: Report of the Association Internationale pour l'Etude des Argiles (AIPEA) Nomenclature. Clays and Clay Minerals 54, 761-772, doi:10.1346/ccmn.2006.0540610 (2006).

227 Theng, B. K. G. \& Yuan, G. Nanoparticles in the soil environment. Elements 4, 395-399 (2008).

228 Tournassat, C., Bourg, I. C., Steefel, C. I. \& Bergaya, F. in Developments in Clay Science Vol. 6 (eds Christophe Tournassat, Carl I. Steefel, Ian C. Bourg, \& Faqpza Bergaya) 5-31 (Elsevier, 2015).

229 Hansel, C. M. et al. Secondary mineralization pathways induced by dissimilatory iron reduction of ferrihydrite under advective flow. Geochimica Et Cosmochimica Acta 67, 2977-2992, doi:10.1016/s0016-7037(03)00276-x (2003).

230 Treves, D. S., Xia, B., Zhou, J. \& Tiedje, J. M. A two-species test of the hypothesis that spatial isolation influences microbial diversity in soil. Microbial Ecology 45, 20-28, doi:10.1007/s00248002-1044-x (2003).

231 Biesgen, D., Frindte, K., Maarastawi, S. \& Knief, C. Clay content modulates differences in bacterial community structure in soil aggregates of different size. Geoderma 376, doi:10.1016/j.geoderma.2020.114544 (2020).

232 Pascual-Garcia, A., Bonhoeffer, S. \& Bell, T. Metabolically cohesive microbial consortia and ecosystem functioning. Philosophical Transactions of the Royal Society B-Biological Sciences 375, doi:10.1098/rstb.2019.0245 (2020). 


\section{Acknowledgements}

We acknowledge the constructive suggestions of three anonymous reviewers. ICB was supported by the U.S. Department of Energy, Office of Science, Office of Basic Energy Sciences, Geosciences Program under Award DE-SC0018419. SCBM was supported by the NSF (CHE; Award: 1609927). CMH's contribution was supported by NSF award EAR 1826940.

\section{Author contributions}

All authors participated in developing the concept. Figures were developed by E.C. (Figures 1 and 5), M. K. (Figure 2), I.C.B. (Figures 3 and 4), S.M. (Figure 6), C.M.H. (Figure 7) and N.N. (Figure 8). All authors contributed to writing and editing.

\section{Competing interests}

The authors declare no competing interests.

\section{Peer review information}

Nature Reviews Earth \& Environment thanks M. Aeppli, L. Aristilde and the other, anonymous, reviewer(s) for their contribution to the peer review of this work.

\section{Publisher's note}

Springer Nature remains neutral with regard to jurisdictional claims in published maps and institutional affiliations.

\section{Key points}

- Minerals enable the compartmentalisation of soils and sediments into small yet clearly delineated spaces such that different chemical, ecological and evolutionary processes can occur concurrently within a larger system context.

- Organic matter $(\mathrm{OM})$ attachment to mineral surfaces is dynamic, sensitive to interfacial energies and topology, and exhibits features reminiscent of a partial wetting phenomenon.

- Mineral-derived reactive oxygen species represent overlooked but undeniably key reactants in the oxidation and transformation of OM within soils and sediments.

- Correlations between OM and fine-grained minerals, though generally interpreted as reflecting the impacts of minerals on OM, could additionally reflect impacts of OM on mineral nucleation, growth, and transformation.

- Depending on system logistics and environmental setting, the same type of mineral could act as a sorbent, chemical reactant and catalyst for associated OM, enabling a vast portfolio of potentially opposing outcomes. 
- Assessments regarding the fate of OM in the environment should not be derived from correlations with single predictor values, such as abundance of a certain mineral phase or specific surface area.

\section{Figure Captions}

Figure 1 Organic-matter cycling in soils and sediments and mineral-organic matter interactions a| Historic representation of organic matter cycling in soils and sediments. Major organic matter (OM) pools and fluxes are represented as black boxes and arrows. Blue arrows represent processes and interactions discussed in this Review. $\mathbf{b} \mid$ Multiscale representation of mineral organic interactions. At the largest scale (Tier 1), the main function of the mineral matrix is to delineate compartmentalized space. As a consequence of compartmentalization, a number of static and dynamic constraints are imposed on smaller scales (Tier 2 functions). These constraints then determine the intensities and rates at which molecular scale biogeochemistry could be able to proceed (Tier 3 functions).

Figure 2. Organic Multifunctionality. Variation of functional group combinations on organic compounds allows for diverse modes of interaction with mineral surfaces.

Figure 3. Key properties of fine-grained minerals and related solids. The material referred to as allophane is a short-range-ordered (SRO) phyllosilicate with imogolite-like local structure and highly variable stoichiometry; its distinguishing features are low crystallinity and transmission electron microscopy (TEM) images suggestive of hollow spheres 3.5 to $5 \mathrm{~nm}$ in diameter, though multiple studies have noted that the interpretation of three-dimensional structure from twodimensional TEM image is ambiguous ${ }^{95}$. Data based on $\operatorname{Refs}^{34,66,94,96,226-229}$.

Figure 4. Size, shape, and global distributions of minerals. a| Size and shape of minerals discussed here. $\mathbf{b} \mid$ Global map showing the most abundant fine-grained mineral in the subsoil ( 0.3 to $2 \mathrm{~m}$ depth) as a function of location, and average relative abundance of different finegrained minerals in the upper $2 \mathrm{~m}$ of soil averaged over the Earth's land surface with the exception of organic-rich soils (such as mollisols) and ice-covered regions ${ }^{33}$. Part $\mathrm{X}$ is adapted from ref ${ }^{33}$, CC BY 4.0 (https://creativecommons.org/licenses/by/4.0/).

Figure 5. Organic ligands at mineral interfaces. Mineral interfaces occur at a variety of spatial scales and topography in soils and sediments, where a diversity of primarily low-molecular weight, amphiphilic organic ligands may reach the solid-solution interface. Once proximal, 
ligands can bind to mineral surfaces through one or multiple complexation mechanisms based on surface charge distribution and structural reactivity.

Figure 6. Molecular mechanisms of $\mathrm{OM}$ reactions at mineral-water interfaces. Cartoon at the top shows a mineral surface showing monolayer and multilayer (3-dimensional) sorption of small and large OM. Molecular structures of organic molecules at mineral-water interfaces are: i: cation bridging, ii: H-bonded or Lifshitz - Van der Waals interactions, and iii: direct covalent interactions. Expanded views of OM interactions and expected trends for different mineral structures in soils and sediments are shown at the bottom. The nature of chemical reactions are (as numbered in the figure): 1: e-transfer and electrolytic breakdown of OM; 2: larger OM formation from nucleophilic addition and radical mediated polymerization; 3 : hydrolytic breakdown of molecules from $\mathrm{pH}$ changes at the interface; 4 : heterogeneous $\mathrm{OM}$ oxidation from adsorbed $\mathrm{O}_{2}$; and 5: chemical changes to substrate showing electron transfer and reduction of substrate atoms and changes to the coordination environments of neighboring atoms of substrate surface. Based on their differences in chemical reactivity towards OM, we further classify minerals presented above into 3 classes (I-III). Expected trends for OM behavior are included.

Figure 7. Mineral-induced organic carbon redox pathways. a| Mineral induced oxidation, which represents direct coupling. b| Mineral-derived aqueous Fe(II), which involved both direct and reactive oxygen species (ROS) mediated reactions. c| ROS mediated reactions. In $\mathbf{b}$ and $\mathbf{c}$, the fate of mineral-derived ROS includes reaction of ROS with organic carbon (OC) or transformation of one ROS to another (dismutation of superoxide to hydrogen peroxide, formation of hydroxyl radical from ferrous iron and hydrogen peroxide via the Fenton reaction) for simplicity, all these fates are not shown here. The illustrations are meant to show general processes, not mechanistic details, and the list of reactions is not exhaustive.

Figure 8. Compartmentalization and mineral-organic matter-microbe interactions. Top panel shows structure with high clay content that is compartmentalized and relatively constant over time and lower panel shows structure with low clay content that is relatively dynamic over time. The compartmentalization and constant micro-environmental conditions results in greater niche differentiation, which allows a greater microbial diversity to co-exist through reduced competitive interactions ${ }^{230,231}$. The magnified insets show potential evolutionary consequences in microsites that form constant habitats. The capacity to use organic substrate present is subjected to strong selective pressure and preserved but other pathways could be lost (insets $i$. and iii.). Less competitive species do not compete for organic substrate present, but exploits metabolic by-product of more competitive species, resulting in a better use of available resources by the microsite community ${ }^{232}$ (insets ii. and iv.).

\section{Glossary Terms}


Adsorption - An increase in the concentration of a dissolved substance at the interface of a condensed and a liquid or gaseous phase due to the operation of surface forces.

Catalyst - A substance that increases the rate of a reaction without modifying the overall standard Gibbs energy change in the reaction

Chemotrophic - the ability to use electron donors other than photons for the synthesis of organic compounds containing reduced carbon

Coagulation - the formation of aggregates from a fluid colloidal system

Colloid - molecules or polymolecular particles dispersed in a medium that have at least in one direction a dimension roughly between $1 \mathrm{~nm}$ and $1 \mu \mathrm{m}$

Colloidal interactions - interactions that are enabled when particles become so small (equivalent diameter $<1-2$ micron) that surface borne electric forces between particles can effectively control their behavior in a suspension (for instance, prevent them from settling)

Compartmentalization - the division of a system into multiple subsystems with well defined boundaries that provide a certain degree of process autonomy

Coulombic interactions - interactions that result from the electric force between two charged entities

Crystal facet - a flat plane on a crystal

Crystal growth - the addition of new atoms into the characteristic arrangement of the crystalline lattice, releasing thermal energy (enthalpy of crystallization)

Depolymerization - the disassembly of a polymer into its constituent monomers or into a mixture of products

Dispersion - A system in which particles of colloidal size of any nature (solid, liquid or gas) are dispersed in a continuous phase of a different composition (or state).

Fine-grained fraction - mineral grains with an average diameter smaller than 50/63 microns, depending on classification system used

Heterotrophic - the ability to derive nutritional requirements from complex organic substances

Intra-particle region - any part of a particle that is not participating in surface reactions

Interfacial energy - excess free energy or work associated with the interface between two phases, per interfacial area

Ligand - any atom or molecule attached to a central atom, usually a metallic element, in a coordination or complex compound; if regarding part of a polyatomic molecular entity as central, then the atoms, groups or molecules bound to that part are called ligands.

Metabolic dependency - a form of adaptation that leads to the absence or loss of the ability to synthesize a certain metabolite essential for the organism, usually in response to an abundance of said compound in the environment

Microsite - a clearly delineated space within an environment with unique conditions or features in which specific microbial processes can occur. 
Mixotrophic - deriving carbon and energy from a mix of different sources, typically a combination of inorganic and organic compounds

Nanowire - proteinaceous appendage produced by microbes, particularly bacteria, that is electrically conductive

Nucleation - the process by which nuclei are formed in solution

Orientational freedom - the absence of any physical restrictions to the movement and arrangement of a compound

Passivated - a surface that is unreactive owing to alteration or from the formation of a thin inert coating

Photochemical lability - the tendency of a compound to undergo a chemical reaction when exposed to light

Phototrophic - ability to capture photons as energy source for the synthesis of organic compounds containing reduced carbon

Poorly crystalline - an operational term to distinguish crystalline structures with short range order from others that exhibit order over longer distances

Reactive oxygen species - ROS are short-lived oxygen-bearing molecules with half-lives that range from fractions of seconds to days, including hydrogen peroxide $\left(\mathrm{H}_{2} \mathrm{O}_{2}\right)$, superoxide $\left(\mathrm{O}_{2}{ }^{-} / \mathrm{HO}_{2}\right)$, hydroxyl radical $\left(\mathrm{HO}{ }^{\bullet}\right)$, singlet oxygen $\left({ }^{1} \mathrm{O}_{2}\right)$, and carbonate radical $\left(\mathrm{CO}_{3}{ }^{-{ }^{-}}\right)$.

Ripening - physical and/or structural alteration of a mineral to obtain a lower surface free energy and more energetically favorable state

unsaturated soil - a (soil) pore system that is only partially filled with water is unsaturated; a pore system entirely filled with water is considered saturated.

Short-range ordered - the regular and predictable arrangement of atoms over a very short distance; in crystals, order does not persist over distances of more than a few nanometers and often extends over the distance of just a few bond lengths; Short range ordered minerals are often also referred to as poorly crystalline minerals.

Solution - a homogeneous phase that results from the mixing of two (or more) phases

Steric constraints - factors or effects that either prevent the adoption of a certain spatial orientation that would be required for the reaction to proceed unhindered

Steric enhancement - factors or effects that facilitate the adoption of a certain spatial orientation that would be required for the reaction to proceed unhindered

Xenobiotic compound - a substance that is foreign to a given natural environment or ecosystem; usually means that organisms in the system lack adaptations for the metabolic processing of a xenobiotic compound

\section{Table of contents summary}

Minerals and organic matter interact in soils and sediments, impacting biogeochemical cycling and ecosystem functioning. This Review describes the major and emerging environmental mineral-organic interactions observed, and their implications for organic matter persistence. 
1506

1507

1508

1509 